\title{
Consumo de tabaco en Santiago de Chile durante el periodo tardío colonial e inicios de la era republicana
}

\author{
JUAN JosÉ MarTínez BARRAZA
}

\begin{abstract}
PALABRAS CLAVE: consumo de tabaco, Santiago de Chile, mercado colonial, niveles de vida.
\end{abstract}

CÓDIGOS JEL: N26, N36, N76, N96.

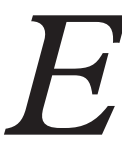

ste trabajo muestra el consumo de tabaco en Santiago de Chile desde el último

tercio del siglo XVIII hasta las primeras décadas republicanas, y con ello des-

taca un positivo elemento del nivel de vida de esta sociedad, en contraste a la visión menos optimista de Allen, Murphy y Schneider (2012) para la América borbónica en general. En base a registros contables de la administración del Estanco, se compilan los valores de comercio del segmento de estanqueros, incluyendo precios y volúmenes de ventas de tabaco, para visualizar el consumo efectivo de la población santiaguina. Los resultados muestran que el valor de consumo de tabaco en este periodo aumentó, en línea con el crecimiento demográfico de Santiago y pese al alza de sus precios medios. En cuanto al volumen, este consumo superó las tres libras per cápita por año a fines del periodo colonial, mientras que en las primeras décadas republicanas bajó a niveles de dos libras. Esta evolución se explicó por el cambio de la pauta de consumo santiaguina, cuya preferencia colonial por tabacos de menor elaboración para labores de humo perdió terreno ante un mayor surtido de productos refinados después del periodo revolucionario de la década de 1810. Más importante aún, el acceso al tabaco debió ser universal, toda vez que su gasto significó solo un 2,5\% del ingreso anual de un trabajador con la menor calificación de la época. 


\title{
Tobacco consumption in Santiago de Chile during the late colonial and early Republican era
}

\author{
KEYWORDS: tobacco consumption, Santiago de Chile, colonial mar- \\ ket, living conditions.
}

JEL CODES: N26, N36, N76, N96.

his article assesses the consumption of tobacco in Santiago de Chile from the
last third of the eighteenth century until the first decades of the republican era.
Evidence indicates a rather favourable standard of living in Bourbon America, in contrast with the less optimistic view portrayed by Allen, Murphy and Schneider (2012). The methodology employed here consisted of compiling the trading values of the tobacconist profession, including prices and volumes of tobacco sales, in order to visualize the effective consumption of the population through the use of documentary sources from the Chilean general tobacco administration. The results show that tobacco consumption increased in Santiago during this extended period, in line with population growth and despite the rise in the average price of tobacco. In terms of volume, legal consumption of tobacco exceeded 3 pounds per capita per year at the end of the colonial period, while in the early republican decades it dropped to 2 pounds. This evolution can be explained due to the transformation of the consumption pattern in Santiago, where the colonial preference for less elaborated tobacco gave way to a greater assortment of refined products after the revolutionary period that began in 1810. More importantly, access to tobacco would have been universal, since on average it cost only $2.5 \%$ of the annual income of the least qualified workers.

Recibido: 2017-05-01 - Revisado: 2017-11-01 - Aceptado: 2017-11-17

Juan José Martínez Barraza es estudiante del programa de doctorado en Historia de la Universidad de Santiago de Chile (USACH) y becario CONICYT. Trabaja como investigador asociado en el Centro Internacional de Investigación de Historia Económica, Empresarial y de la Administración Pública (CIHEAP), en la Facultad de Administración y Economía de la USACH. Dirección para correspondencia: Av. Libertador Bernardo O’Higgins, 3363, Comuna Estación Central, Santiago de Chile (Chile). E-mail: jj.martinez.barraza @gmail.com 


\section{INTRODUCCIÓN}

El objetivo de este trabajo es aproximarse al nivel real de consumo de tabaco en Santiago de Chile durante el último tercio del siglo XviII y las primeras décadas republicanas, lo cual representaría una nueva evidencia de un estándar de vida de su población superior al que estiman Allen, Murphy y Schneider (2012) para la América borbónica en general. Como consecuencia, este estudio ex ante apoya la visión optimista de una creciente línea de investigación ${ }^{1}$ de las condiciones de vida hispanoamericanas durante el periodo virreinal, en contraste con la negativa posición que le asignan los partidarios del neoinstitucionalismo, al compararlas con la América del Norte británica y el noroeste de Europa. Tal como plantea Dobado (2015:39, 46), no solo existen diferencias importantes entre los hipotéticos consumos que utilizan Allen, Murphy y Schneider (2012: 873) y los niveles que sugiere la evidencia para la América española, por ejemplo relativos a un producto como la carne, sino que adicionalmente se excluyen ciertos bienes que contribuyen a la noción de un bajo estándar de vida con que se evalúa a esta región ${ }^{2}$. Además de azúcar, alcoholes y cacao, otra importante omisión corresponde al tabaco, cuyo consumo was present in the everyday lives of many Spanish Americans, representando una proporción significativa de las rentas fiscales. Esto pese a que, salvo en Nueva España y Cuba, su demanda fue probablemente menos generalizada (Dobado, 2015: 47).

En Chile, la escasa historiografía al respecto señala que el fumar fue una costumbre natural e imprescindible, incluso entre mujeres y niños, entregándose todas las clases sociales [...] por igual al vicio del tabaco (Stapff, 1961: 20-22; Villalobos \& Sagredo, 2004: 80). Pese a que este hábito estaba diversificado, principalmente se trataba del producto en rama proveniente de Saña (Perú), cuyo menor costo lo hacía favorito por los fumadores modestos de las ciudades, incluidos los obreros mineros, mientras que el tabaco en polvo para aspirar, de origen cubano en mayor proporción, se consumía casi exclusivamente en los círculos más adinerados, dado su alto valor y distinción ligada a su gasto (Villalobos \& Sagredo, 2004: 72, 81; Stapff, 1961: 20-21). Durante el año 1791 el consumo de tabaco en rama en la ciudad de Santiago fue de 80.672 mazos, equivalentes a 110.924 libras $^{3}$, mien-

1. Dobado y García Montero (2009, 2014a, 2014b); Dobado (2009, 2015); Arroyo, Davies y ZANDEN (2011); y, para el caso chileno, LlorCA y NAVARRETE (2015).

2. La falta de representatividad de la canasta de consumo con que Allen, Murphy y Schneider evalúan las condiciones de vida de la América española se evidencia de manera empírica para Nueva España y Buenos Aires, respectivamente, en CALDERón (2016: 132-144) y SANTILLI y GELMAN (2016: 128-134).

3. Cada mazo igual a 22 onzas, en LAviANA (1985: 68-69; Fisher, 1999: 43; EsCOBAR, 2004: 83). Una libra igual a 16 onzas, en CARRERA (1949: 13). En adelante, los volúmenes de tabaco que originalmente se contabilizaron en mazos se convierten a libras para su comparación con otros mercados. 
tras que los niveles de tabaco en polvo superaron las 4.000 libras (Villalobos \& Sagredo, 2004: 81). Una década y media después, la venta de tabaco en polvo en todo el Reino de Chile superaba las 9.000 libras (Stapff, 1961:21).

Pese a esta evidencia, los estudios de precios, salarios reales y condiciones de vida -todos los cuales requieren de estructuras de gasto de los hogares para sus estimaciones-, o no incluyen el tabaco (Salinas, 1974-1975; Quiroz, 2009, 2012; Arroyo, Murphy \& Schneider, 2011; Llorca \& Navarrete, 2015) o lo consideran de manera parcial (Ramón \& Larraín, 1982) ${ }^{4}$. Este sesgo se debe a la parcialidad de sus fuentes, dada la población en condición de reclusión a la cual interrogan por medio de cuentas de gastos de instituciones eclesiásticas, educacionales, militares, incluidas las relativas a la construcción de obras públicas, todas las cuales no contemplan la provisión de un vicio como el tabaco.

Ante la ausencia de antecedentes históricos relativos al real peso del tabaco sobre el consumo de la población chilena, en contraste con la incidencia de su renta en el erario fiscal durante el periodo de transición colonial al republicano, este trabajo pretende, en particular para la ciudad de Santiago, incluidos sus espacios rurales contiguos: a) determinar la magnitud y estructura comercial del tabaco e incidencia en el consumo, integrando el estudio de precios, volúmenes y valores de ventas; b) destacar el papel de los consumidores y la evolución de sus pautas de consumo en la formación de la sociedad chilena moderna; y c) instalar este hallazgo en un contexto en que la discusión historiográfica sobre la divergencia económica se basa en escasa evidencia empírica, usualmente de Nueva España y un par de espacios hispanoamericanos, asumiendo con ello una alta homogeneización de las condiciones materiales del resto de las economías de esta vasta región.

El plan de esta obra incluye, además de esta introducción, cuatro secciones más las conclusiones. En la primera de ellas se presentan el objeto de estudio, la metodología y las fuentes documentales. En la sección siguiente se contextualiza el monopolio de tabaco chileno en perspectiva sistémica, considerando en especial el régimen imperial colonial en que se desarrolló esta institución durante buena parte del periodo en estudio. En las tres secciones siguientes se muestran los principales resultados empíricos de esta investigación: en primer lugar, la magnitud y evolución del comercio de tabaco en Santiago, en contraste con los beneficios de esta renta, como evidencia de su importancia para el suministro de la población; seguidamente, la estructura del comercio tabaquero, desta-

4. Estos autores estiman la inflación chilena del periodo $1659-1808$ por medio de una canasta de bienes que contiene solo tabaco en polvo, cuya ponderación es de 1,1\% sobre el gasto total del quinquenio base 1754-1758 (RAMÓN \& LARRAín, 1982: 381). 
cando las características de la oferta y el funcionamiento de los estanquillos; a continuación, se exponen los volúmenes y precios de venta de los tabacos y la evolución de los hábitos de consumo en Santiago, así como una aproximación al grado de acceso a estos productos por parte de su población. Finalmente, se presentan las principales conclusiones de este trabajo.

\section{METODOLOGÍA Y FUENTES}

La atención sobre el consumo constituye un intento por revalorar una historiografía, cuyo análisis debiese integrar los diversos elementos que intervienen en este fenómeno para así contribuir al conocimiento del por qué crecen las economías (Quiroz, 2006). En particular, el estudio del consumo de tabaco en Santiago de Chile, que habitualmente se concibe como una economía marginal, en buena medida por falta de evidencia que muestre lo contrario, importa en primera instancia para valorar su incidencia sobre el desarrollo de la Hacienda. Así, este enfoque busca valorar el papel de los consumidores en el mercado que abastecía a Santiago y de esa manera evaluar si su dinamismo tuvo una magnitud tal que permita conocer mejor las reales condiciones de vida de su población. Dado el contexto político imperial en que se instauró el Estanco en Santiago (Náter, 2006; Luxán \& Gárate, 2010), la valoración de su demanda no se restringe solo a los efectos sobre su mercado interno ni tampoco al más amplio chileno, sino que se extiende sobre el resto de las regiones que integraron este eje comercial. Pese a las restricciones del monopolio, importa dar cuenta de la real capacidad que tuvo esta población periférica para afectar la economía de la extensa cadena regional que se desarrolló en torno al suministro de tabaco.

Para llevar a cabo estos objetivos, el enfoque histórico regional de O'Brien (1982), Assadourian (1983) y Garavaglia (1983) permite configurar un espacio privilegiado de análisis de las principales variables asociadas al consumo de una población objetivo. En particular, de uno de los indicadores básicos para medir condiciones de vida, como lo es el consumo per cápita, de lo cual poco se conoce históricamente con respecto a Chile ${ }^{5}$.

De esta manera, la apuesta de valor de este trabajo se basa en su distinción respecto de los estudios que ponen énfasis en la incidencia de la renta del tabaco sobre el erario chileno $^{6}$ (Silva, 1968: 156-171; Stapff, 1961: 26-27; Villalobos \& Sagredo, 2004: 83-87;

5. Algunos avances al respecto, en SALINAS (1974-1975) y QuIROZ (2012).

6. Estudios pioneros en esta línea para Guayaquil, Lima, México y Nueva Granada, respectivamente, en Laviana (1985), Fisher (1999), DeAns-Smith (1999), Acevedo y Torres (2016). Para 
Folchi \& López, 2010: 15). Un aspecto relevante al respecto es que el beneficio del Estanco puede revelarse desde diversas perspectivas de la contabilidad en el contexto borbónico. Por un lado, como valor líquido, cuyo nivel equivalía al caudal disponible para la Corona después de descontar de los ingresos por la venta de tabacos de un año corriente, incluido el valor de existencias de ejercicios anteriores, la suma de los gastos operativos respectivos, además del situado y la inversión en obras de fortificación del Reino de Chile ${ }^{7}$. Mientras que, desde la perspectiva de la Real Hacienda, la renta del tabaco correspondía solo al monto del situado o paga a las dotaciones militares (Klein \& TePaske, 1982; Folchi \& López, 2010: 16) ${ }^{8}$. Esto implica la necesidad de aislar estas variables respecto de la evolución efectiva que tuvieron las ventas como indicador del consumo. En particular, el valor líquido en un año corriente, al concebirse como la diferencia entre ingresos y gastos, respondió a un conjunto mayor de factores, incluidos los relativos a la defensa pública, cuyo carácter estratégico ciertamente distó del fenómeno de consumo y la demanda respectiva que se pretende valorar en este trabajo.

Bajo este enfoque, el límite espacial de esta investigación corresponde al otrora corregimiento de Santiago, perteneciente al obispado homónimo ${ }^{9}$, cuya superficie abarcó, además del casco urbano, su zona rural circundante, la cual se dividió en doctrinas, jurisdicción política eclesiástica que se remonta a principios de la época colonial (Sociedad Bibliográfica, 1895: 162) ${ }^{10}$. En 1786, con la creación de las intendencias en Chile, el corregimiento se denominó partido de Santiago (Barros, 2001, vi: 328-329), continuando así hasta la primera mitad del siglo XIX.

A diferencia de Stapff, y Villalobos y Sagredo, quienes cubren en general el territorio chileno, este estudio se concentra en el corregimiento/partido de Santiago por su im-

un análisis general de la renta del tabaco en la Hacienda española, véase GonZÁLEZ ENCISO (2006).

7. Los gastos operativos más importantes eran compras de tabacos, remuneraciones y comisiones por ventas, fletes y arriendos. Detalle para los años 1772 y 1784, en el Archivo Nacional de Chile, fondo Contaduría Mayor, serie 1, vol. 972, fj. 38; serie 2, vol. 3153, fj. 45. El valor líquido resultante se asemeja al valor útil neto o líquido disponible de las provincias de Valencia y Alicante, en SOLBES (2007a: 280-286).

8. La historiografía de la Hacienda española identifica distintos valores líquidos, dependiendo de la deducción que se hiciera sobre la renta de los diversos gastos asociados: Con todo, no se trata nunca del «valor neto» final, pues en la renta se detraían una gran cantidad de otros conceptos a los que se hacía frente (RODRÍGUEZ GORDILLO, 2007: 36).

9. Esta jurisdicción comprendió además, de norte a sur, los corregimientos de Copiapó, Coquimbo, Aconcagua, Quillota, provincia de Cuyo, Valparaíso, Melipilla, Rancagua, Colchagua y Maule.

10. Las doctrinas del corregimiento de Santiago fueron: Colina, Til-Til, Lampa, Quilicura, Renca, Chuchunco, Santa Cruz, Tango, Ñunoa y El Salto, cuya superficie corresponde aproximadamente a la actual región metropolitana de Chile. 
portancia histórica, en términos demográficos y socioeconómicos, respecto del resto de las localidades de la capitanía de Chile. Según cifras del primer censo del obispado de Santiago, en 1778 la mayor densidad demográfica se concentraba en este espacio (Barros, 2001, VI: 271; VII: 324-327; Encina, 1970: 361), cuyos 38.330 habitantes representaban el $21,6 \%$ de la población de esta jurisdicción mayor (Carmagnani \& Klein, 1965). Esta proporción se incrementó sostenidamente, alcanzando a 60.000 habitantes en $1810 \mathrm{y}$ alrededor de 80.000 individuos a principios de 1840 (Ramón, 2007: 91, 185) ${ }^{11}$.

Respecto de la temporalidad, el periodo de estudio se justifica por la histórica trayectoria económica que vivió Santiago a partir de la segunda mitad del siglo XvIII. Durante esta época la actividad comercial interna de Santiago experimentó un sostenido crecimiento (Carmagnani, 2001: 179), producto de la creciente urbanidad (Ramón, 2007: 89129), que incentivó el aumento de la oferta de moneda fraccionaria para facilitar su funcionamiento (Quiroz, 2012: 94-105) y, pese a la consecuente inflación de precios (Ramón \& Larraín, 1982: 336), los salarios reales se mantuvieron por sobre los niveles de subsistencia en la capital (Llorca \& Navarrete, 2015: 89). Posteriormente, desde 1810 a 1830, la naciente República de Chile, pese a las distorsiones del proceso emancipador, habría ingresado con éxito en la economía mundial, sobre todo durante la década de 1820, debido al dinamismo de su producción interna y al intercambio comercial con otras regiones del mundo (Llorca \& Navarrete, 2016: 13).

El método general de trabajo consiste en compilar el valor de comercio del tabaco para consumo en Santiago, a partir de la agregación de las ventas de cada uno de los establecimientos que abastecieron a este espacio. En consecuencia, la fuente documental principal corresponde a las rendiciones de cuentas de cargo y data que registraban los oficiales de contaduría y tesorería de la administración de esta capital para el control y gestión del almacén, la tercena y los estanquillos de la ciudad, a través de los cuales se distribuía el tabaco al público en general ${ }^{12}$. En particular, se distinguen las cuentas de cargo o de abastecimiento de tabacos desde el almacén hacia los estanquillos, cuyos niveles incluían existencias de años anteriores y del año en curso ${ }^{13}$, de las cuentas de data o ventas efectivas de dichos establecimientos, cuya estacionalidad difiere de la provisión de estos puntos de

11. Esta población se compara sobre los 26.125 y 42.540 habitantes que en 1778 y 1810 , respectivamente, se estiman para Buenos Aires, en Johnson, Socolow y SEIBERT (1980: 331).

12. Documentación existente en varios volúmenes del Archivo Nacional de Chile (ANCH), fondo Contaduría Mayor (FCM), series 1 y 2.

13. Similarmente, en España durante el siglo XviII se contabilizaban los alcances o existencias de tabaco al comienzo de cada ejercicio en la cuenta de cargo (LuxÁn, 2007a: 116). 
venta $^{14}$. Sin embargo, la escasa disposición de estas fuentes impide reconstruir series continuas de las variables de interés. Como consecuencia, se compilan solo los años con información completa, cuya riqueza, en términos de precios, volúmenes y valores de ventas por tipo de tabaco ${ }^{15}$ y lugares de expendio permite reconstruir una muestra representativa de la evolución del consumo en Santiago. En complemento, se utilizan estudios demográficos y laborales para compilar indicadores per cápita y del poder de adquisición del tabaco por parte de la población.

Por último, se recopilan cuentas de valores enteros o abonos en dinero efectivo por las ventas que periódicamente remitían los estanqueros de Santiago a la Administración, cuyos niveles, a diferencia de otros mercados ${ }^{16}$, no revelan necesariamente las transacciones efectivas de estos agentes, pero sí permiten visualizar otras variables de interés, tales como su cuantía, los tipos de tabaco en venta y sus precios respectivos.

Cabe destacar que los resultados de esta investigación, como es habitual cuando se utilizan fuentes fiscales, constituyen solo un piso de la evidencia que se pretende establecer con respecto al consumo de tabaco en Santiago. Esto es debido a la omisión inevitable de segmentos y canales informales de comercio que representaron, más aún bajo el régimen monopólico al cual estuvo sujeta esta actividad, sectores ilegales permanentemente sofocados por las autoridades a lo largo de todo Chile.

\section{MONOPOLIO DE TABACO EN CHILE BAJO EL SISTEMA ATLÁNTICO}

Desde inicios de la conquista americana por los españoles, la Corona articuló un restrictivo sistema comercial en el que las colonias se limitaban a remitir los metales preciosos a través de un mercado cerrado por el monopolio metropolitano (Fisher, 1999: 36; Náter, 2006: 206). Bajo este esquema, surgió una compleja red de producción, traslado y distribución de productos tabaqueros entre América y Europa, lo que algunos autores denominan el sistema atlántico del tabaco, el cual, luego de despegar durante el siglo XVII,

14. Se excluyen de esta contabilidad las ventas de gergas o envases para el tabaco en rama, tarros de plomo para almacenar tabaco en polvo y papeles para confeccionar cigarros que, en conjunto, representaron una proporción mínima de los ingresos del Estanco.

15. Los registros de ventas en todo el periodo distinguen dos tipos de tabacos, por libras y por mazos, lo que no siempre coincide con sus labores respectivas. Si bien desde los inicios del Estanco el tabaco en polvo, cuya labor era aspirarlo, fue la única variedad que se contabilizó en libras, a partir de 1810 se surtieron nuevos tabacos en este mismo formato, aunque para labores de humo.

16. Por ejemplo, en las provincias de Valencia y Alicante, cuyo valor entero refleja en un 99 por 100 los ingresos por ventas de tabaco (SOLBES, 2007a: 280). 
cambia sustancialmente en el siglo XVIII, dentro de un marco institucional que tiende a las prácticas monopolísticas (Luxán \& Gárate, 2010: 147). La transformación de este sistema, elemento central del plan de reformas borbónicas de la Hacienda para incrementar las arcas metropolitanas, implicó el surgimiento de los monopolios del tabaco en las colonias, principalmente para financiar la defensa global del Imperio (Náter, 2006: 205, 216; Vizcarra, 2006: 231; Luxán \& Gárate, 2010: 169-175) ${ }^{17}$. De esta forma, la creación de monopolios desde la segunda mitad del siglo XviII respondió a la lógica de organización territorial americana, es decir, fueron independientes entre si y del estanco peninsular, aunque se creasen según su modelo (Luxán \& Gárate, 2010: 175), dejando al descubierto un complejo engranaje productivo comercial entre las colonias (Náter, 2006: 227). Uno de estos ejes, situado al margen de los principales canales de producción y circulación del sistema atlántico del tabaco ${ }^{18}$, se constituyó en torno a los primeros monopolios que en la práctica funcionaron bajo el esquema reformista borbón: Perú (1752) y Chile (1753) (Stapff, 1961: 6; Fisher, 1999: 42). Dada la dependencia política y financiera de la capitanía de Chile al virreinato del Perú, la administración de estos estancos, al menos en su primera etapa, estuvo sujeta a la Dirección General de Tabacos de Lima (Stapff, 1961: $5-6,13)$. Como consecuencia, las autoridades peruanas fomentaron su producción en las provincias norteñas de Saña y Chachapoyas para cubrir los consumos de Chile y Lima, respectivamente. Sin embargo, las actividades se limitaron al cultivo de tabaco para la producción en rama, siendo insuficiente la oferta a estos mercados (Fisher, 1999: 43-44; Escobar, 2004: 27-33; Náter, 2006: 220, 223). En este contexto, se sumó a la escasez de tabaco en rama, la preferencia de los consumidores limeños por el tabaco en polvo (Náter, 2006: 220; Alonso, 2006: 251-252), en adición a la demanda chilena por esta última variedad. El tabaco faltante, por tanto, debió proveerse por la vía transpacífica, esto es, tabaco en rama y en polvo principalmente desde La Habana, vía Panamá, y también este último en menor proporción desde Nueva España, vía Acapulco, para abastecer el mercado limeño y desde ahí el chileno vía Callao-Valparaíso (Fisher, 1999: 43). Dada su posición importadora neta, se identifica a este eje como monopolio consumidor dentro del sistema tabaquero colonial (Náter, 2006: 220-223) ${ }^{19}$.

17. La historiografía de Perú al respecto plantea más bien que el fin supremo del Estanco fue la salud del pueblo, mediante el control de la calidad del tabaco (FISHER, 1999: 42-43; Escobar, 2004: 1920).

18. Cuatro fueron los ejes principales del sistema atlántico del tabaco: Chesapeake (Virginia)-Londres, Glasgow-Holanda-Francia, Bahía-Lisboa-Mina-España y Nueva España-Cuba-Sevilla (Cádiz) (LUXÁn \& GÁrATE, 2010: 147).

19. Lima fue el segundo destino de las exportaciones de tabaco cubanas, alcanzando el $29 \%$ de este mercado entre 1763 y 1812 , así como el mayor consumidor de tabaco en polvo del mismo origen, con un 57\% de participación (NÁTER, 2006: 222-223). 
Respecto del monopolio en Chile, fue en Santiago, a partir de mayo de 1753, cuando comenzó a operar por instrucción del virrey Manso de Velasco la administración del Real Estanco de Tabaco. Este organismo tuvo como objeto distribuir monopólicamente el tabaco provisto desde Lima y, con ello, destinar sus rentas al reemplazo del situado que se enviaba año a año desde el virreinato para la manutención del sistema de defensa militar chileno (Barros, 2001, vi: 142; Stapff, 1961: 25-26; Silva, 1968: 163-164; Villalobos \& Sagredo, 2004: 70) ${ }^{20}$. Como consecuencia, a diferencia de antaño, se prohibió el cultivo de tabaco y su venta por canales particulares, bajo amenaza de graves penas, mediante la fiscalización periódica de esta administración, cuyo celo evitaba la introducción clandestina y la agricultura ilegal. Desde este organismo, además, se administró la recepción, almacenamiento y distribución del tabaco hacia el resto de las localidades chilenas (Barros, 2001, vI: 142-143; Stapff, 1961: 7-8, 48; Villalobos \& Sagredo, 2004: 63, 66, 70). Durante las últimas décadas del periodo colonial prácticamente todas las jurisdicciones de la capitanía, incluidos sus puntos fronterizos y aislados como Chiloé, Valdivia e Isla Juan Fernández, contaban con administraciones particulares para el Estanco de Tabaco, las cuales administraban alrededor de trescientos estanquillos en todo el territorio (Stapff, 1961: 29) ${ }^{21}$. Si bien, desde un principio, el financiamiento y gestión del Estanco corrió por parte de las autoridades limeñas, a partir de 1786 esta situación cambió al asumir la administración santiaguina el costo y administración del tabaco que se suministraba al reino (Stapff, 1961: 34, 42; Villalobos \& Sagredo, 2004: 75; Escobar, 2004: 25).

Posteriormente, la emergencia del proceso independentista chileno amenazó la estabilidad del monopolio vigente. Así, en el año 1811, a un año de la primera Junta de Gobierno de Chile, se autorizó el cultivo interno de tabaco, pero la medida se revirtió en 1815, luego de que las fuerzas realistas recobraran el poder y restablecieran el régimen de estancos anterior a 1810. Dos años después, tras el triunfo definitivo del ejército patriota en 1817, si bien se restauró el cultivo local, se prohibió el libre comercio, quedando el fisco a cargo de la compra y reventa, además del estanco de los tabacos importados (Lavaud, 1996: 36-42). Un año más tarde, las autoridades revirtieron esta medida, lo cual originó un descenso de las rentas fiscales por el deterioro de los ingresos aduaneros debido al remplazo del tabaco importado por el cultivo nacional. Esta crisis motivó el restablecimiento del estanco de tabaco importado en 1820, lo que provocó fuerte resistencia de los comerciantes que ya habían invertido en este negocio. A raíz de este reclamo, al año siguiente

20. Producto de estos situados o subsidios enviados desde Lima, Chile fue beneficiario neto de las transferencias entre colonias durante este periodo (GRAFE \& IRIGOIN, 2006: 252; IRIGOIN \& GRAFE, 2006: 24).

21. Para conocer el número y distribución de las administraciones particulares durante 1788,1791 , 1799 y 1808, véase VillaLobos y SAGREdo (2004: 67-69, 85-87). 
se liberó nuevamente la venta de tabacos en polvo y rama, aunque con altas tasas arancelarias sobre la internación ( $40 \%$ ad valorem), lo que afectó a la importación e incentivó el contrabando. Esto provocó la reacción de las autoridades que revocaron tal medida en 1822, volviendo al régimen monopólico inicial y prohibiendo el cultivo interno (Lavaud, 1996: 45-47). Un año después, en aquel contexto de urgencia financiera para sostener el proyecto republicano que inclúa significativos gastos en defensa, se aprobó la entrega del Estanco a privados mediante subasta pública, medida que afectó la distribución de tabacos extranjeros de cualquier clase, e incluyó también el expendio de naipes, vinos y licores importados, dejando libre solo el cultivo nacional de tabaco en rama. Esto significó que en agosto de 1824 la firma Portales, Cea y Cía. se adjudicara el monopolio por el término de diez años, asumiendo el riesgo de compra y venta y distribución de los productos estancados, además del pago programado de una millonaria deuda contraída en Londres por el gobierno chileno (Kyonen, 1955: 36-60; Encina, 1970: 777-779; Lavaud, 1996: 4857). Sin embargo, el contrato se rescindió poco después, en septiembre de 1826, debido al incumplimiento financiero de los empresarios, cuestión que llevó a las autoridades a trasladar nuevamente el Estanco a la administración del fisco (Kyonen, 1955: 81). Bajo este nuevo régimen se crearon administraciones subalternas en cada partido de Chile, que sumaban un total de 37 en 1845, sentando con ello las bases de la administración hacendística nacional debido a su presencia en todo el territorio (Villalobos \& Sagredo, 2004: 113-114). En 1847, Santiago ya contaba, además de su administración urbana, con cuatro administraciones subalternas, las cuales distribuían el tabaco por todo el entorno rural que comprendía el antiguo corregimiento (Lavaud, 1996: 93-94).

\section{COMERCIO DE TABACO EN SANTIAGO DE CHILE}

Una primera aproximación a la cuantía del comercio estancado de tabaco en Chile, por medio de las rentas que ingresaron a la Real Hacienda del virreinato de Perú entre 1755 y 1774, indica que la administración de Santiago, a cargo del obispado homónimo, lideró la participación con 2.062.776 pesos (pesos de ocho reales), seguida de la Dirección de Lima que alcanzó a 1.290.256 pesos, mientras que Concepción registró 404.454 (Amat y Junient, 1947: 573); es decir, poco más de dos tercios de esta renta se devengaron a partir de la demanda chilena por tabaco ${ }^{22}$. Hacia fines de la época colonial las rentas del tabaco aportaban a la Hacienda chilena alrededor del $50 \%$ de los ingresos totales (Stapff, 1961: 26-27; Villalobos \& Sagredo, 2004: 87). Esta proporción fue decreciendo gradualmente hasta alcanzar el 10\% en 1880, año en que se abolió el Estanco (Lavaud, 1996:

22. Aunque su mayor proporción quedó en Chile, ya que se destinó al pago del situado de esta capitanía y la inversión para fortificar la plaza de Valdivia (AMAT y JUNIENT, 1947: 574-575). 
150-151). Al centrar el análisis en la evolución de las ventas efectivas de tabaco en Santiago, se revela una ligera trayectoria ascendente, aunque con leves altibajos, desde niveles de 80.000 pesos en 1769 hasta valores superiores a 130.000 en el año 1839. Esto implica un crecimiento promedio anual de $0,7 \%$, en términos nominales ${ }^{23}$, resultado que, como se espera para la evolución del consumo, es consistente con el crecimiento de 1,3\% de la población chilena durante el periodo 1790-1835 (Díaz, Lüders \& Wagner, 2016: 597). El comportamiento del consumo, en definitiva, contrasta con la evolución dispar de la renta del tabaco, según se observa al comparar con los distintos valores que representaron este beneficio (Gráfico 1).

\section{GRÁFICO 1}

\section{Evolución de la venta de tabaco en la ciudad de Santiago y renta del Estanco del} obispado de Santiago, 1755-1839

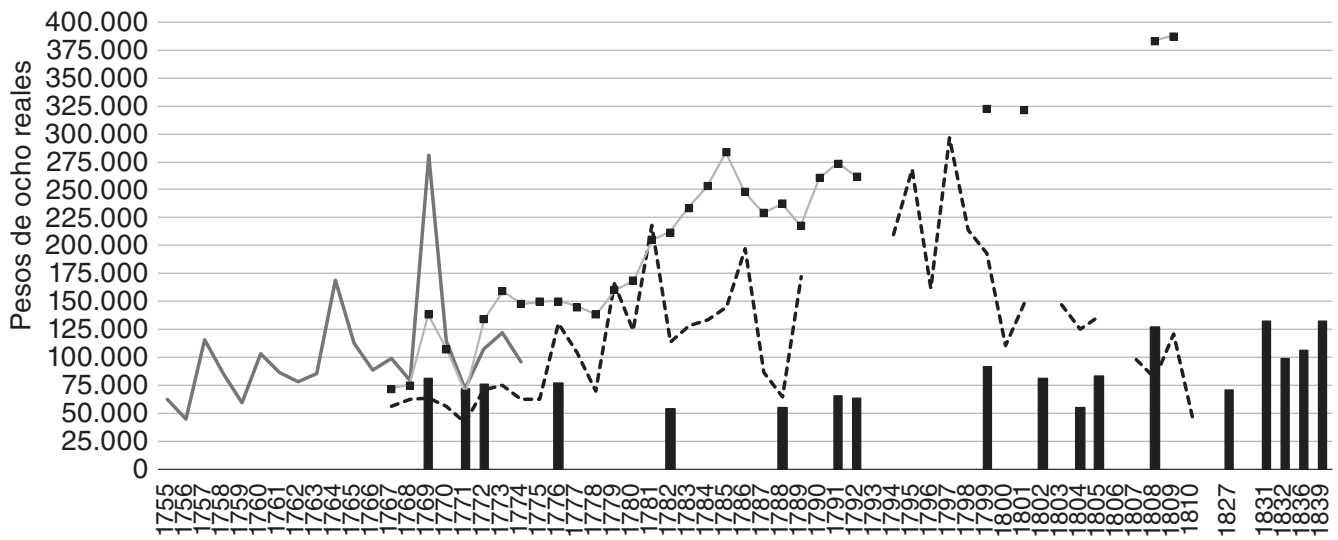

--- Renta de Tabaco de ciudad de Santiago

- Renta Obispado Santiago (Amat, 1947)

- Renta Obispado Santiago (V\&S, 2004)

Fuentes: elaboración propia a partir de ANCH, FCM, serie 1, vol. 962, fjs. 169, 171; vol. 972, fj. 30; vol. 979, fjs. 137-151; vol. 980, fjs. 175-342; vol. 989, fjs. 60-65; vol. 1027, fjs. 3-332; serie 2, vol. 283, fjs. 9v.11; vol. 284, fjs. 1-64; vol. 286, fjs. 1-13v.; vol. 287, fjs. 1-78; vol. 288, fjs. 1-12v.; vol. 3153, fjs. 25-26; vol. 3155, fjs. 1-33; vol. 3156, fjs. 1-31; Amat y Junient (1947: 573); Klein y TePaske (1982); Lavaud (1996: 88, Anexo 1); Villalobos y Sagredo (2004: 83, 86-87).

Al comparar las ventas de tabaco en Santiago con el resto de las localidades del obispado/intendencia homónimo, más Concepción, que en conjunto representaban cerca de un $85 \%$ de este mercado en Chile ${ }^{24}$, se muestra el liderazgo de la capital, cuya participación promedió poco más del 40\% durante el periodo tardío colonial (Cuadro 1).

23. Esto es, a precios corrientes de cada año.

24. Estimación para 1791, 1792, 1799 y 1808, a partir de ANCH, FCM, serie 2, vols. 3155-3156; Villalobos y SAGREDo (2004: 85-87). 
Pese al liderazgo de Santiago, pierde terreno en la era republicana, debido al progreso del resto de las provincias de la intendencia. En particular, sin contar Concepción, que durante buena parte del periodo ocupó el segundo lugar, hasta principios de 1790 las provincias de Quillota y Talca lideraban después de Santiago la participación sobre las ventas del obispado. Sin embargo, a partir de fines de esta década fue el puerto de Valparaíso y sus zonas aledañas los mercados de mayor incidencia sobre esta jurisdicción.

$\mathrm{Al}$ agregar el Estanco de Tabaco de Santiago con los valores de comercio interno respectivos (Carmagnani, 2001: 174, 386-388) ${ }^{25}$, que incluyeron una surtida provisión de mercancías locales y ganado en pie (Martínez, 2016: 138-140), el primero representó en promedio un $17 \%$ sobre el total de esta agrupación ${ }^{26}$ (Cuadro 1).

En síntesis, un primer aspecto relevante de las ventas de tabaco en Santiago es que su magnitud y evolución difieren de la renta del Estanco que habitualmente destaca la historiografía, ya que se trata de variables de naturaleza distinta. En particular, la trayectoria del consumo es consistente con el crecimiento vegetativo de la población, lo que constituye un primer indicio de que el gasto en tabaco habría sido universal entre los grupos sociales de la época. En segundo lugar, pese al liderazgo santiaguino en el mercado colonial del tabaco chileno, pierde participación debido al avance del resto de las provincias, en especial anteValparaíso, localidad portuaria que a fines del siglo xvIII experimentó un sostenido auge económico y demográfico, producto del aumento del comercio exterior y la producción minera (Carmagnani, 2001; Cavieres, 2008; Llorca \& Navarrete, 2016). Finalmente, el contraste entre las ventas de tabaco y los valores de comercio interno revela una primera aproximación del peso real de este producto sobre el consumo capitalino, pese a la omisión en este análisis de mercancías de origen extra reinal, no afectas a gabelas y provistas por canales informales.

25. La expansión de los valores de comercio interno se obtiene a partir de la recaudación de alcabalas, cuyo monto reflejaba el $4 \%$ del valor de las mercancías que se internaban para reventa y consumo en Santiago hasta el año 1819. Posteriormente, se expanden a razón de $6 \%$, debido al alza impositiva (CARMAGNANI, 2001: 174-175).

26. Agrupación de comercio que no incluye los segmentos informales, ni el comercio de abastos, que estaba exenta del pago de alcabalas por la venta de alimentos de primera necesidad (MARTínEZ, 2016: 50-51). 


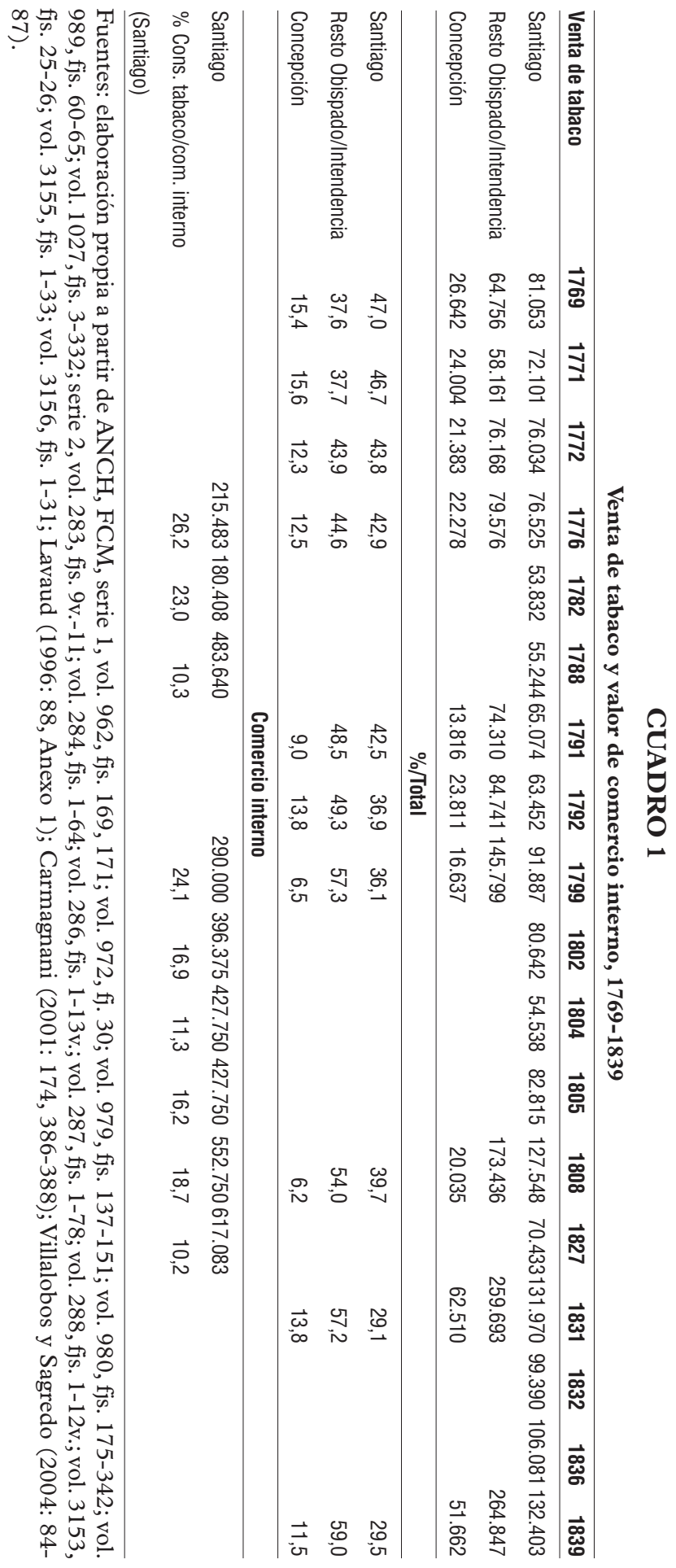




\section{ROL DE LOS ESTANQUEROS Y FUNCIONAMIENTO DE LOS ESTANQUILLOS}

Desde la perspectiva de los agentes que abastecían de tabaco al público en general, los estanqueros cumplían un rol central en la administración de los estanquillos o puntos de venta, donde se expendía al detalle el tabaco que consumía la población chilena. A diferencia de los funcionarios remunerados de la Administración, los estanqueros fueron comisionistas, ya que recibían un porcentaje ad valorem de las ventas que ejecutaban. A través de las cuentas de data y enteros, se constata que durante el periodo inicial del Estanco las comisiones fueron diferenciadas, según giro comercial del estanquillo. Mientras los estanqueros especializados en el comercio de tabaco en polvo recibían el $10 \%$ del valor de sus ventas, aquellos que expendían tabaco en rama obtenían solo el $5 \%$ respectivo, por lo menos hasta $1772^{27}$. Esta diferencia se eliminó años después, al igualarse en $10 \%$ el premio por venta de cualquier tabaco -tal como revelan los registros administrativos de 1776 y $1777{ }^{28}$, porcentaje de comisión que se mantuvo durante las décadas posteriores.

Una de las preocupaciones fundamentales de la administración del Estanco, además de combatir la producción ilegal y el comercio clandestino ${ }^{29}$ y asegurar la provisión de tabacos a los puntos de venta, era fiscalizar el correcto funcionamiento de los estanqueros. Con relación a la mantención de los tabacos, estos debían velar por el buen acomodo que corresponde, en estribarlos con correspondientes abrigos para que se preserven de la humedad, separándolos en sus frascos respectivos hasta que vaya a darse a la venta. Respecto del control de la correcta comercialización y satisfacción de la clientela, destacó el celo de la administración por el respeto de la cuota de venta que se asignaba a cada uno de los estanquillos, así como también de los precios establecidos del tabaco, para lo que debían poner diariamente en las puertas de las oficinas las tarifas que las gobiernan, procurando además no vender producto mezclado con otros de contrabando, ni tampoco efectos distintos al Estanco. En cuanto a las obligaciones con la clientela, debían tener a la vista en sus mostradores los pesos, debidamente arreglados para el expendio de tabaco en polvo, así como también las medidas ajustadas con que se menudean los Mazos de Tabaco en rama. El horario de atención debía ser puntual ${ }^{30}$, esto es, los estanquillos se abri-

27. ANCH, FCM, serie 1, vol. 3153, fs. 25-26. Hasta el año 1772, los porcentajes de comisión por tipo de estanquillo fueron comunes en todo el virreinato de Lima (EsCOBAR, 2004: 24).

28. ANCH, FCM, serie 2, vol. 286, fjs. 1-13v.; vol. 288, fjs. 1-12v.

29. Ejemplos de esta regulación, en ANCH, FCM, serie 1, vol. 961, fj. 120 y ss.; FCM, serie 2, vol. 292.

30. Carta del escribano de la administración de Santiago con fecha 21 de agosto de 1780, en 
rían desde bien temprano en la mañana hasta las diez de la noche (Villalobos \& Sagredo, 2004: 74). La fiscalización del Estanco se ajustaba, por tanto, al esquema del Antiguo Régimen que dominaba principalmente el quehacer del Cabildo (Alemparte, 1966), sobre todo en materia de regulación de los segmentos que abastecían las mercancías de primera necesidad a la población.

En complemento a la oferta de estanqueros, el suministro de tabaco en Santiago se completaba por medio de la tercena y el almacén, cuya operación estaba a cargo del tercenista y el fiel de almacén, respectivamente, ambos funcionarios remunerados de la Administración ${ }^{31}$. Estos establecimientos se ubicaban en inmuebles arrendados para concretar desde ahí una pequeña porción de las ventas al detalle e incluso al por mayor ${ }^{32}$.

Una aproximación al número de estanquillos de Santiago se muestra en el Gráfico 2. Durante la década de 1770, operaban en promedio 33 estanquillos al año, cifra superior a los 16 y 4 puntos de venta que atendían la provisión de tabaco de Lima y Guayaquil en la segunda mitad del siglo XVIII, respectivamente (Fisher, 1999: 44; Laviana, 1985: 83). Alrededor de un tercio de estos establecimientos se especializaba en el expendio de tabaco en polvo, cuya principal clientela correspondía al grupo de mayor renta, que, a semejanza de la costumbre española, aspiraba dicho producto. Los dos tercios restantes proveían de manera exclusiva el tabaco en rama, fumable en papel o liado en sus propias hojas, proporción que preliminarmente concuerda con la escasa evidencia de su mayor consumo en Chile (Stapff, 1961: 20-21; Lavaud, 1996: 88, Anexo 1; Villalobos \& Sagredo, 2004: $81)$.

Respecto de la distribución de estos lugares de comercio, la dirección designaba su ubicación según demanda por jurisdicción y vecindario. Sin embargo, como no siempre se satisfacían las expectativas de ventas de los estanqueros, fueron recurrentes las irregularidades por mejores posturas para aumentar las ganancias. En este contexto, para auxiliar las sobrecargadas funciones de la Dirección General, se creó en 1781 la administración particular de Renca, doctrina contigua al límite urbano de Santiago, donde se establecieron de 15 a 20 estanquillos adicionales al casco de esta ciudad, cuya oferta ma-

ANCH, FCM, serie 1, vol. 971, fjs. 2-3v. Las mismas normas se aprecian dos décadas después, en ANCH, FCM, serie 2, vol. 321, fjs. 98-100v, "Informe del Director General del Real Estanco», 1809. 31. Sueldos de estos funcionarios en 1788, 1804 y 1805, en Villalobos y SAGREdo (2004: 67; ANCH, FCM, serie 1, vol. 962, fjs. 62-122, 152-160).

32. Detalle de arriendos en 1804 y 1805, en ANCH, FCM, serie 1, vol. 962, fjs. 157v., 160. Detalle de estas ventas en 1769 y 1771, en ANCH, FCM, serie 2, vols. 283, fjs. 8, 10; vol. 284, fjs. 2-3v., 19-21v. 
yoritaria fue el tabaco en rama de Saña ${ }^{33}$. Como consecuencia, la Dirección de Santiago en materia de estanquillos, se restringió a los límites urbanos, donde operaron cerca de 19 establecimientos hasta la década de 1810, mientras que Renca ya contaba con 22 en $1801^{34}$. Esta reorganización del Estanco en Santiago revela la intención de las autoridades por satisfacer al más amplio público, mediante la presencia de estanquillos en todos sus rincones (Villalobos \& Sagredo, 2004: 69). Incluso en áreas de difícil acceso, como fueron los distintos pasos cordilleranos que unían el comercio chileno con las provincias trasandinas del virreinato de La Plata.

\section{GRÁFICO 2}

Número de estanquillos de tabaco y promedio total en el corregimiento/partido de Santiago, 1771-1841

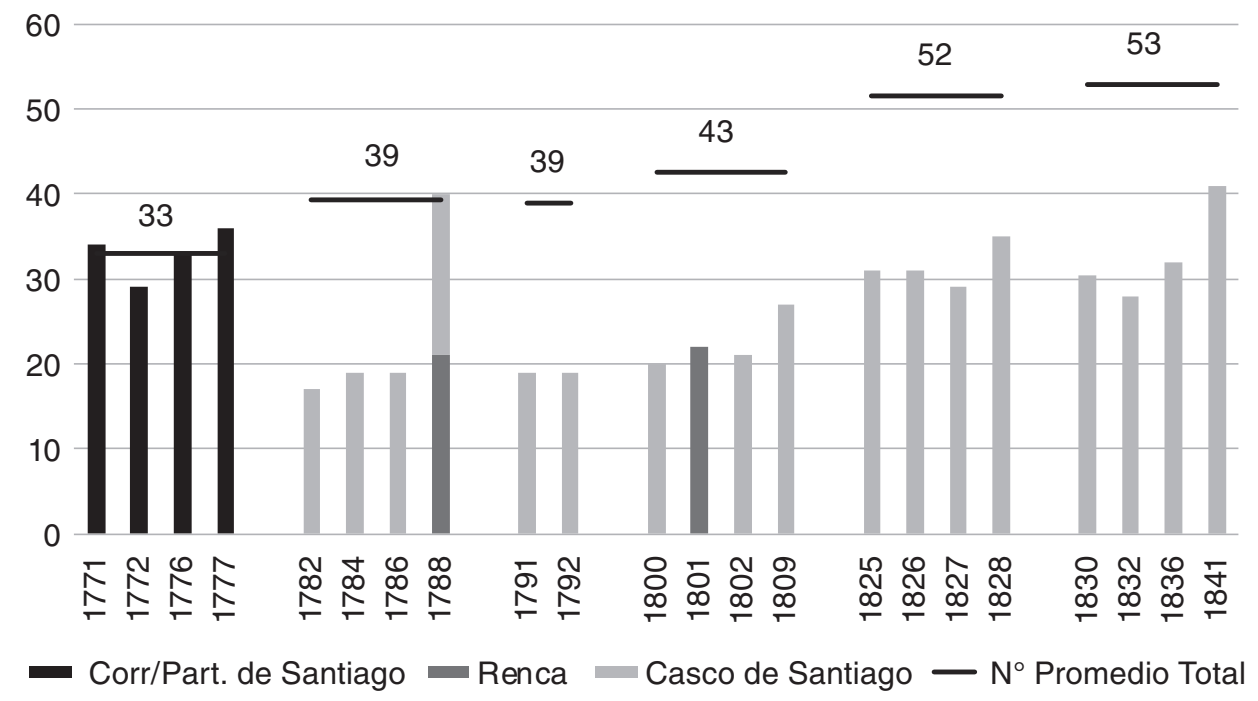

Fuentes: elaboración propia a partir de ANCH, FCM, serie 1, vol. 963, fjs. 43-50; vol. 972, fjs. 30, 54; vol. 979, fjs. 137-151; vol. 980, fjs. 175-342; vol. 984, fjs. 368-369v.; vol. 988, fjs. 101-102v.; vol. 989, fjs. 6065; vol. 1027, fjs. 3-332; serie 2, vol. 284, fjs. 1-64; vol. 287, fjs. 1-78; vol. 288, fjs. 1-12v.; vol. 294, fjs. 34v.; vol. 295, fjs. 1-19; vol. 321, fj. 99; vol. 3153, fjs. 25-26; vol. 3155, fjs. 1-33; vol. 3156, fjs. 1-31; vol. 3157, fjs. 95-96v.; Lavaud (1996: 113-116); Villalobos y Sagredo (2004: 67-69).

A partir de 1809, se evidencia un alza en el número de estanquillos urbanos, alcanzando en promedio a 30 por año, los que en adición a Renca, sumaron alrededor de 50 puntos de venta en el interior del partido de Santiago (Gráfico 2). Cifra similar a los 49 establecimientos que abastecían a Madrid a inicios del siglo XIX (Luxán, 2007a: 151). En suma, el crecimiento promedio anual de estanquillos santiaguinos fue de $0,7 \%$ durante todo el

33. ANCH, FCM, serie 2, vol. 321, fjs. 60v, 98-100v.

34. ANCH, FCM, serie 1, vol. 988, fjs. 101-2v. 
periodo, resultado que se ajusta a la evolución de los niveles de venta y población de este mismo espacio.

Según la normativa inicial del Estanco, el giro comercial de los estanquillos debía ser único no pudiendo vender licores, especias, olores ni otras mercaderías que dañasen los tabacos (Villalobos \& Sagredo, 2004: 74). Sin embargo, en 1781 esta oferta se amplió con la incorporación al Estanco de pólvora, barajas y papel sellado ${ }^{35}$. Este surtido continuó hasta 1823, cuando se aprobó una nueva extensión del giro de los estanquillos que incluyó té, vinos y licores importados.

La participación de la tercena y almacén en 1769, 1771, 1776, 1791, 1792 y 1832 alcanzó en promedio un 10\% del valor de la oferta de tabaco. El 90\% restante de las ventas se distribuyó entre los estanqueros de Santiago, cuya comisión promedio por ventas aumentó significativamente después de 1772 (Gráfico 3), cuando subió del 5\% al 10\% el premio por expendio de tabaco en rama de Saña.

\section{GRÁFICO 3}

\section{Comisión promedio anual por estanquero de tabaco en Santiago, 1769-1839}

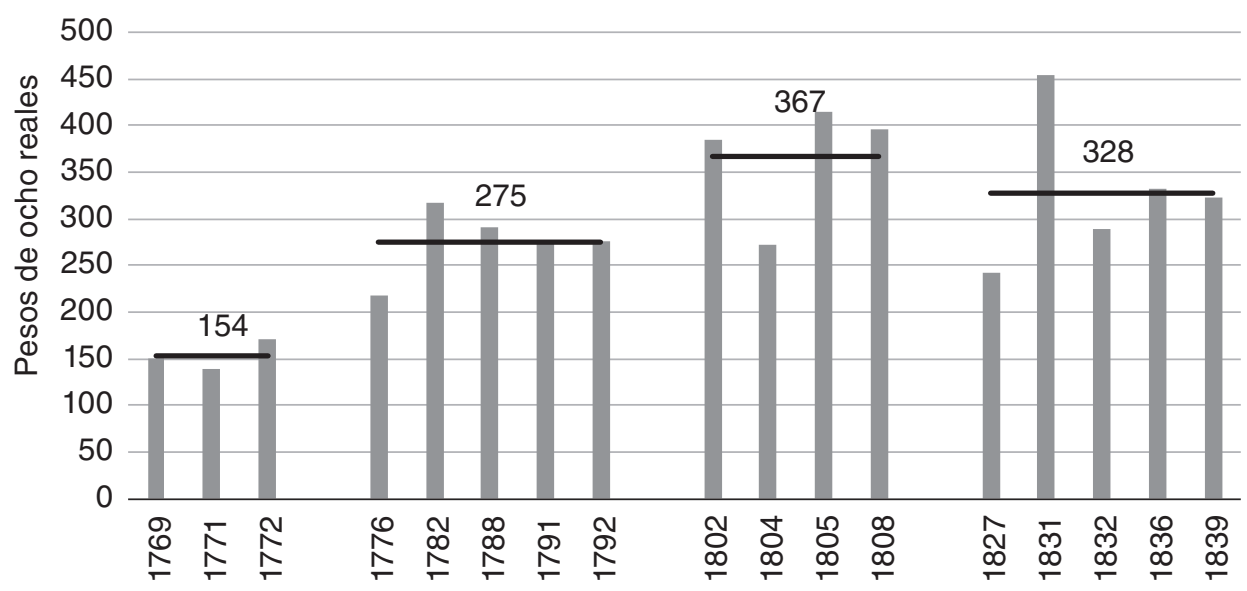

- Comisión promedio por estanquero -Nivel promedio por periodo

Fuente: elaboración propia a partir de ANCH, FCM, serie 1, vol. 962, fjs. 169, 171; vol. 963, fjs. 43-50; vol. 972, fj. 30; vol. 979, fjs. 137-151; vol. 980, fjs. 175-342; vol. 989, fjs. 60-65; vol. 1027, fjs. 3-332; serie 2, vol. 283, fjs. 9v.-11; vol. 284, fjs. 1-64; vol. 287, fjs. 1-78; vol. 321, fj. 99; vol. 3153, fjs. 25-26; vol. 3155, fjs. 1-33; vol. 3156, fjs. 1-31; Lavaud (1996: Anexo 1); Villalobos y Sagredo (2004: 67-69, 86-87).

35. ANCH, FCM, serie 2, vol. 321, fjs. 60v-61. 
$\mathrm{Al}$ comparar estos ingresos con las remuneraciones de otros asalariados a mediados de la década de 1770 en Santiago (Quiroz, 2009: 229; 2012: 116; Llorca \& Navarrete, 2015: 84), los estanqueros obtenían en promedio montos anuales superiores en cuatro veces el salario efectivo, esto es, excluyendo el valor de alimentación que se daba en el trabajo, de un trabajador urbano no calificado (peón), poco menos de tres veces el ingreso de un oficial albañil o el doble de un maestro carpintero. Los ingresos de estanqueros, más bien, se comparaban con el salario de un médico del Hospital San Francisco de Borja de Santiago, cuyo nivel era de 300 pesos por año a fines del siglo $\mathrm{xvIII}^{36}$.

\section{GRÁFICO 4}

Venta mensual de tabacos en Santiago, 1771, 1827 y 1832

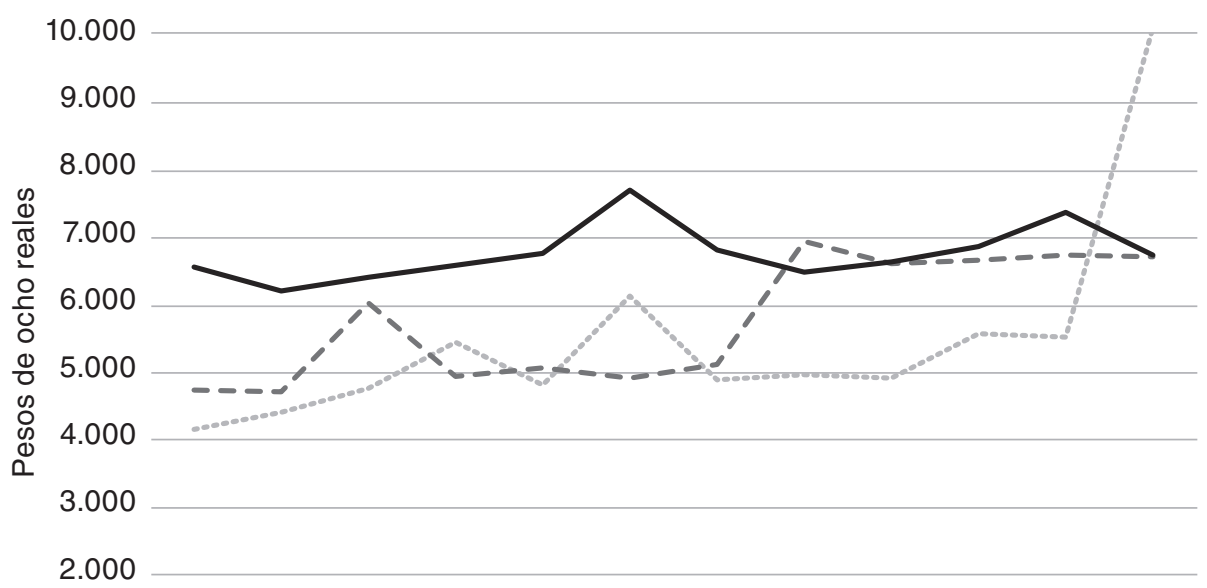

1.000

0

Ene Feb Mar Abr May Jun Jul Ago Sep Oct Nov Dic Año 1771 - - Año 1827 - Año 1832

Fuentes: elaboración propia a partir de ANCH, FCM, serie 1, vol. 979, fjs. 137-149; vol. 1027, fjs. 3-332; serie 2, vol. 284, fjs. 1-64.

Sin embargo, esta alta media de ingresos no fue sinónimo de una distribución homogénea entre los estanqueros capitalinos. En promedio durante este periodo, el 50\% de los comisionistas se repartió cerca del $20 \%$ de los premios por ventas en la capital. Mientras que en 1832, cuyo balance fue el más desigual, solo el $10 \%$ de los estanqueros obtuvo la mitad de las ganancias. Pese a esta heterogeneidad, los ingresos aparentes de este segmento igualmente habrían motivado, por un lado, la alta demanda de licencias para establecer

36. Nivel de salario anual entre 1782 y 1792, en ANCH, fondo Hospital San Francisco de Borja, serie Estados Financieros, fjs. 3-230. 
estanquillos ${ }^{37}$ y, por otro, la prolongada presencia de estanqueros en esta actividad, cuya operación superaba, en promedio, los ocho años, encontrándose individuos con más de treinta años de servicio ${ }^{38}$. Por otro lado, al igual que en el resto de los segmentos comerciales minoristas de Santiago (Martínez, 2016: 129-130, 144-225), la participación de mujeres fue prácticamente nula. La única excepción fue doña Constanza Ferrer, quien figuró como estanquera en 1832, aunque solo por los meses de noviembre y diciembre ${ }^{39}$.

De acuerdo con las ventas mensuales de los años 1771, 1827 y 1832, si bien no se aprecia una marcada estacionalidad, sí se observa un sostenido incremento de estos niveles durante el transcurso del año, cuyo máximo se alcanzaba en el mes de diciembre (Gráfico 4). De mayor interés es que estos montos muestran la regularidad con que se abastecía tabaco a lo largo del año, a diferencia de la provisión mayorista de mercancías locales, cuya estacionalidad estaba fuertemente marcada por los ciclos propios de la actividad agropecuaria (Martínez, 2016: 128-129).

\section{CONSUMO DE TABACO EN SANTIAGO}

Las escasas crónicas asocian el uso ancestral del tabaco en Chile al estrato indígena, ya sea para satisfacer el hábito de fumar, como medicina para la asistencia de enfermos por medio de sahumerios e incluso para la ejecución de rituales religiosos (Carvallo, 1876: 10, 14, 138; Pérez García, 1900: 58). En todos los casos, el consumo de tabaco fue en humo, hábito que habría adoptado posteriormente la población blanca dominante, incluso pese a la introducción del tabaco en polvo, cuyo aspirado se reservó al grupo de mayor renta debido a su alto precio relativo. Previo al monopolio, el tabaco era importado principalmente desde Perú por un corto número de comerciantes, quienes, con poco respaldo de otros sectores debido a la exigua producción local, ofrecieron débil resistencia al Estanco en Chile (Barros, 2001, vi: 142; Villalobos \& Sagredo, 2004: 62-65).

Desde comienzos del Estanco en 1753, dos fueron las variedades de tabaco que se surtían a la población santiaguina ${ }^{40}$, en rama y en polvo ${ }^{41}$, las cuales se embarcaban, tal como

37. Solicitudes de estanquillos en 1809, en ANCH, FCM, serie 2, vol. 321, fjs. 33v.-34v., 98-100v. 38. Promedio en base a muestra de 56 estanqueros que participaron en distintos periodos durante $1764,1771,1776,1777,1788,1800,1802,1832$ y 1836 . Cuatro fueron los estanqueros en operación más de treinta años.

39.ANCH, FCM, serie 1, vol. 1027, fjs. 292, 319.

40. Mayoritariamente españoles y mestizos, quienes representaron el $67 \%$ de la población del corregimiento de Santiago, según censo de 1778 (CARMAGNANi \& KLEIN, 1965).

41. Los registros chilenos solo se refieren a tabaco en polvo o polvillo, sin distinción de las varieda- 
en épocas previas, desde el puerto de El Callao, en Perú ${ }^{42}$. De acuerdo a los registros de ventas de estanquillos en Santiago, esta composición se mantuvo durante todo el periodo borbónico, lo que confirma la amplia superioridad del consumo en rama sobre el de polvo. En promedio, hasta la década de 1810, se abastecían poco menos de cinco mil libras de polvo al año, mientras que el tabaco en rama ascendía a casi ciento cuarenta mil libras anuales ${ }^{43}$ (Cuadro 2). Esta composición confirma el dominio del hábito de fumar en Santiago, en contraste al escaso peso del aspirado, a diferencia de las principales economías de referencia (Lima y España), donde esta última labor dominó buena parte del siglo XviII (GRETA, 2002: 314-326; Náter, 2006: 220) ${ }^{44}$.

Durante la década de 1810, cuando se liberó intermitentemente el comercio tabaquero debido a la permanente tensión de las nuevas autoridades entre actuar de acuerdo al liberalismo económico en boga o continuar con la inercia colonial en favor de logros recaudatorios, el surtido de tabaco importado aumentó de manera considerable de la mano de privados. Como consecuencia, a principios de la década de 1820, cuando vuelve la estabilidad del Estanco, se aprecia un notable giro de las preferencias por tabacos de distinta procedencia, tales como picado, habano, virginia y guayaquil, cuya venta se efectuaba por libras (y onzas), lo que restaba participación al producto en rama, abastecido en mazos. La evolución de este patrón refleja la profundización del hábito de fumar entre la población santiaguina, lo cual se tradujo en que la oferta de polvo prácticamente desapareció del mercado (Cuadro 2). Si bien esta pauta de consumo fue similar a la tendencia general del mercado metropolitano de fin del siglo XvIII ${ }^{45}$, las preferencias santiaguinas evolucionaron de manera distinta, transitando desde tabacos de menor a mayor valor, siempre en relación a labores de humo.

des que se aprecian en el centro productor (La Habana) o en las principales regiones consumidoras (GoNZÁleZ FERNÁNDEZ, 1999: 113-114; GRETA, 2002: 323). La evidencia peruana es similar a Chile: los documentos no precisan qué características distinguían al polvo de Lima (NÁTER, 2006: 220; FISHER, 1999: 43).

42. Para mayor detalle productivo del tabaco en el Perú borbón, véanse FISHER (1999: 40-49) y EsCOBAR (2004: 27-71).

43. Este nivel representó cerca de un quinto de la producción anual de Saña, que promedió las 680.000 libras a mediados de la segunda mitad del siglo XVIII (EsCOBAR, 2004: 71), mientras que, con relación a la demanda española del último tercio dieciochesco, se comparó por debajo de las regiones de Sevilla, Galicia, Madrid y Valencia, y por encima de Cataluña, Canarias, Navarra y Soria (GRETA, 2002: 329-343; SOLBES, 2007b: 442; LuXÁN, 2007b: 493).

44. Para el detalle del consumo regional en España, véanse GRETA (2002) y RodRíGUEZ GORDILLO y GÁRATE (2007).

45. A partir de 1779, se consolidó en España el cambio a labores de humo con la aparición de variedades similares al mercado santiaguino (GRETA, 2002: 317-325). 


\section{CUADRO 2}

Consumo de tabaco y población de Santiago, 1769-1836

\begin{tabular}{|c|c|c|c|c|c|c|c|c|c|c|}
\hline Variedad de tabaco & Tipo de labor & r 1769 & 1771 & 1776 & 1791 & 1802 & 1827 & 1831 & 1832 & 1836 \\
\hline Polvo & Aspirado & 6.369 & 4.884 & 5.319 & 3.909 & 3.468 & 0 & 0 & 0 & 0 \\
\hline Saña (vendido por mazos) & Humo & 134.133 & 125.594 & 139.396 & 114.043 & 183.511 & 63.381 & 98.781 & 51.851 & 80.853 \\
\hline Picado & Id. & 0 & 0 & 0 & 0 & 0 & 18.280 & 60.601 & 15.638 & 39.441 \\
\hline Habano & Id. & 0 & 0 & 0 & 0 & 0 & 2.426 & 23.947 & 19.789 & 33.299 \\
\hline Virginia & Id. & 0 & 0 & 0 & 0 & 0 & 22.677 & 19.996 & 24.273 & 1.504 \\
\hline Guayaquil & Id. & 0 & 0 & 0 & 0 & 0 & 1.668 & 499 & 9.678 & 6.927 \\
\hline Bracamoros (id. por mazos) & ld. & 0 & 0 & 0 & 0 & 0 & 974 & 185 & 140 & 0 \\
\hline Virginia (id. por mazos) & Id. & 0 & 0 & 0 & 0 & 0 & 690 & 45 & 1 & 0 \\
\hline Otros ${ }^{*}$ & & 0 & 0 & 0 & 0 & 0 & 0 & 3.490 & 15 & 125 \\
\hline \multicolumn{2}{|l|}{ Total libras } & 140.501 & 130.478 & 144.715 & 117.952 & 186.979 & 110.095 & 207.543 & 121.384 & 162.148 \\
\hline \multicolumn{2}{|c|}{ Población de Santiago } & 38.330 & & & 46.958 & 53.654 & 70.048 & & 78.423 & \\
\hline \multicolumn{2}{|c|}{ Volumen per cápita (libras) } & 3,7 & 3,4 & 3,8 & 2,5 & 3,5 & 1,6 & 3,0 & 1,5 & 2,1 \\
\hline \multicolumn{2}{|c|}{ Valor de consumo (pesos) } & 81.053 & 72.101 & 76.525 & 65.074 & 80.642 & 70.433 & 131.970 & 99.390 & 106.081 \\
\hline \multicolumn{2}{|c|}{ Gasto per cápita (pesos) } & 2,1 & 1,9 & 2,0 & 1,4 & 1,5 & 1,0 & 1,9 & 1,3 & 1,4 \\
\hline
\end{tabular}

${ }^{\star}$ La variedad Otros significa: Otros (Saña [id. por libras], Rapé, breva, Brasil, país, Mendoza).

Fuentes: elaboración propia a partir de ANCH, FCM, serie 1, vol. 972, fj. 30; vol. 979, fjs. 137-151; vol. 980, fjs. 175-342; vol. 1027, fjs. 3-332; serie 2, vol. 283, fjs. 9-11v.; vol. 284, fjs. 1-64; vol. 287, fjs. 1-78; Carmagnani y Klein (1965); Laviana (1985: 68-69); Lavaud (1996: Anexo 1); Díaz, Lüders y Wagner (2016: 597).

Un claro incentivo para este progreso fueron los precios (Gráficos 5 y 6). Mientras el polvo se comercializó a 32 reales de plata por libra, el tabaco en rama de Saña se menudeó a solo 4 reales el mazo durante todo el monopolio borbón. Casi seis décadas después, recién iniciada la crisis independentista, a fines de 1810 se decretó una primera contribución a las ventas del Estanco, elevándose en ocho reales (un peso de plata) la libra de polvo y en un real el mazo de rama (Medina, 1960: 75). Esta medida se reiteró en 1814 solo para el tabaco más popular, ante los mayores apuros de la patria, lo que alzó a 8 reales el mazo de rama (Lavaud, 1996:38-39). En 1824, producto del traspaso del Estanco a privados, los precios se fijaron en 6 reales por libra para los tabacos importados más demandados (virginia, guayaquil y picado), mientras que en 8 reales la variedad habano. En contraste, el polvo continuó su escalada alcanzando los 48 reales/libra. Esta medida también afectó al precio del tabaco en rama, cuyo mazo se redujo a 5 reales (Kyonen, 1955: $53,138)$. Estos niveles continuaron hasta 1846, cuando se decretó una nueva disminución de los precios para desincentivar el contrabando (Lavaud, 1996: 116, 142).

Los precios, por tanto, constituyeron un factor determinante de la nueva demanda santiaguina de tabaco. Pese al alza de los precios medios, desde 4,2 reales/libra en promedio 
durante el periodo borbón hasta 5,5 reales/libra en la década de $1830^{46}$, las cantidades demandadas no declinaron ${ }^{47}$, debido al efecto de dos movimientos de los consumidores que convergieron a acentuar la preferencia por el humo. En primer lugar, del minoritario grupo de rentas altas, antes consumidor de polvo, pero, más importante aún, de una proporción de los sectores medios e inferiores que, pese al aumento de los precios, en comparación al tabaco en rama, cambió su preferencia por variedades de mayor calidad. La combinación de estos dos movimientos explicaría por qué pese al aumento de los precios medios los volúmenes no cayeron, sino por el contrario, se incrementaron aunque moderadamente. Esta dinámica permite descartar un segundo factor explicativo de la evolución de estos hábitos, que apunta al efecto de imitación con que unos grupos sociales se vuelcan a las preferencias de otros, argumento que no es apreciable para el caso santiaguino, donde el contexto político bélico independentista y su probable implicancia sobre el rechazo de costumbres metropolitanas entre los sectores criollos más pudientes pudo ser más decisivo que el efecto de imitación de gustos de estratos inferiores al momento de cambiar sus preferencias por tabacos de humo ${ }^{48}$. Menos evidente aún es que el cambio de las preferencias por tabacos de mayor valor de una proporción de los sectores de menor renta se haya motivado por imitación del grupo más acomodado -cuyo hábito de aspirar después de la crisis imperial prácticamente desapareció-, sino que más bien evolucionó a un estado superior de bienestar, gracias a su efectiva capacidad de adquirir bienes más caros.

Este modelo rescata, por tanto, el activo papel de la extensa masa consumidora de Santiago, cuyo real poder de compra fue capaz de responder cada vez que las autoridades decidieron continuar con el monopolio, pese al sensible gravamen de los conciudadanos (Lavaud, 1996: 39). Era tal la certeza sobre la demanda nacional por tabaco que las estimaciones de su renta por parte del excelentísimo Senado en 1824 se realizaban sobre la base de un millón de habitantes debe ascender el consumo ínfimo de Chile a un millón de masos o libras (Kyonen, 1955: 121) ${ }^{49}$. Así, los beneficios del monopolio se basaban en un

46. Cociente entre valor y volumen de consumo por año, cuyos niveles fueron notablemente inferiores a los precios medios de Madrid para la misma época (LUXÁN, 2007a: 143, 187), debido a la baja incidencia en el mercado santiaguino del costoso tabaco en polvo.

47. A diferencia de España, donde sí caen los volúmenes producto del alza de precios (Alonso, 2006: 254-255; LuXÁN \& GÁRATE, 2010: 170).

48. Así se estima para la España de fin del siglo XviII (Alonso, 2006: 259; LuXÁn, 2007a: 114115).

49. Cifra no alejada de la realidad nacional, cuyo consumo dos décadas después superó las 950.000 libras de tabaco en promedio por año, de las cuales el $70 \%$ correspondió a tabaco en rama de Saña, sin contar los más de 35.500 millones de cigarros puros que también ingresaron entre 1844 y 1854 . Estimación en base a importaciones de tabaco, en LAVAud (1996: 120-122) y VillaLobos y SAGREDo (2004: 116). 


\section{GRÁFICOS 5 y 6}

\section{Precios de venta de tabacos en Chile, 1750-1840}

Precio de tabacos por libras

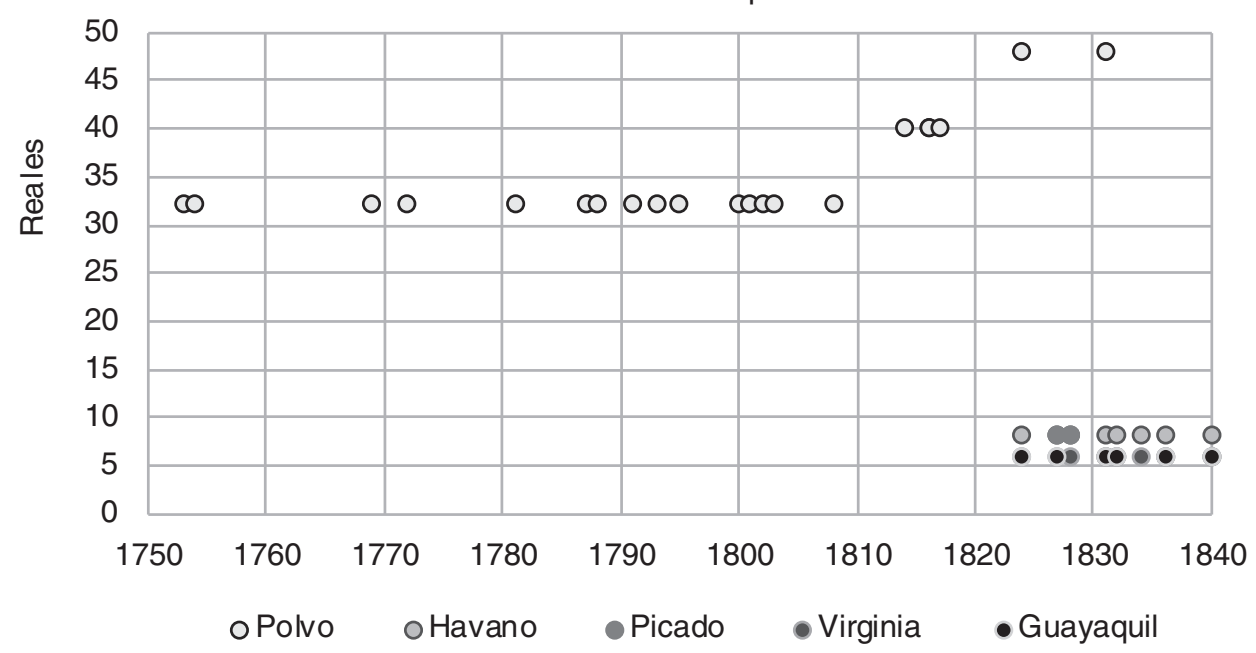

Precio de tabacos por mazos

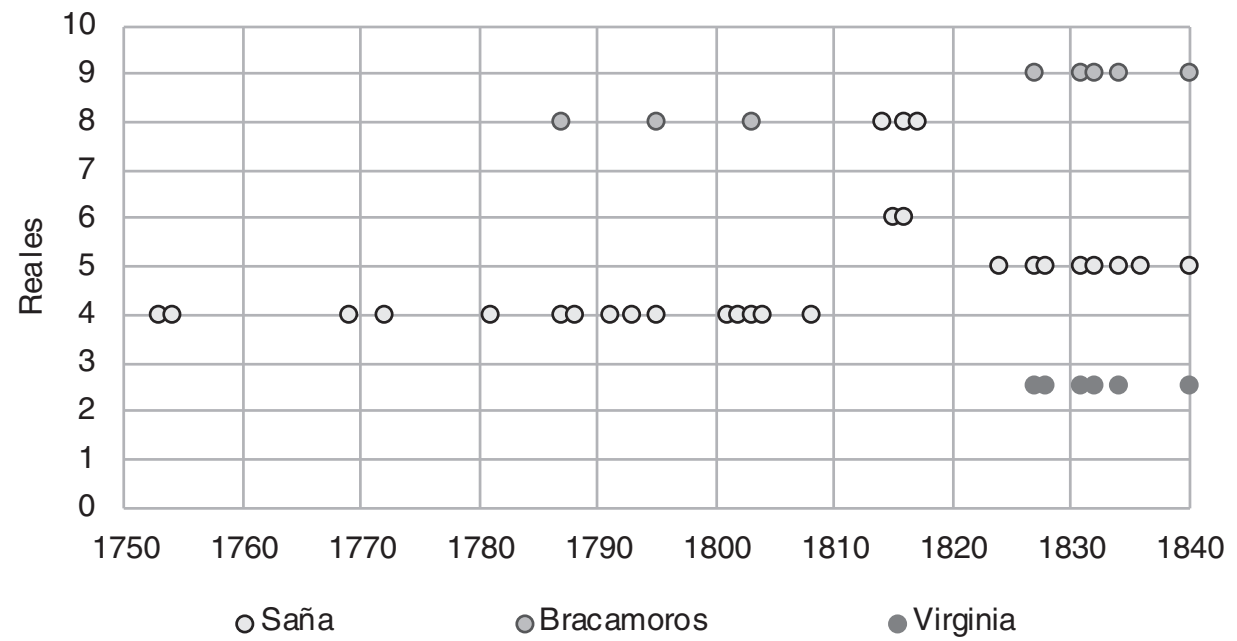

Fuentes: elaboración propia a partir de ANCH, FCM, serie 1, vol. 961, fjs. 5v.-6; vol. 962, fjs. 19, 32, 130, 356-364, 432; vol. 963, fjs. 43-50; vol. 976, fj. 10; vol. 977, fj. 73v.; vol. 979, fjs. 137-151, 168-170; vol. 980, fjs. 175-342; vol. 982, fj. 32; vol. 984, fjs. 368-369v.; vol. 988, fjs. 101-102v., 135v., 145v., 177, 180v., 210 , 233, 252, 268v., 297v., 301; vol. 991, fj. 42; vol. 1027, fjs. 3-332; serie 2, vol. 283, fjs. 2-11; vol. 284, fjs. 164; vol. 287, fjs. 1-78; vol. 289, fjs. 1-43; vol. 305, 82-83; vol. 310, fjs. 95-97; vol. 3153, fjs. 2-3; Pérez García (1900: 372); Kyonen (1955: 53, 138); Lavaud (1996: 116, Anexo 1). 
precio medio de venta de 5 reales/mazo/libra, de cuyo monto se descontaban el costo del tabaco, evaluado en un real la libra de virginia o el mazo de Saña ${ }^{50}$, más un real de gastos por comisiones y labores de venta, quedando para el Estado un margen/impuesto de 3 reales por unidad vendida. De esta forma, el presupuesto de un millón de unidades demandadas se traducía en 375.000 pesos de recaudación al año, que equivalían aproximadamente a la cuarta parte de las entradas fiscales de aquella década (Kyonen, 1955: 118-122; Lavaud, 1996: 150).

En términos del consumo per cápita, Santiago no solo se comparó probablemente por encima de los volúmenes legales de venta del resto de Chile, al promediar 3,4 libras de tabaco por habitante durante el último tercio del siglo XviII, sino que también superó a mercados consumidores como Madrid y Cataluña, cuyas ventas estancadas por individuo promediaron 1,05 y 0,14 libras en la misma época, respectivamente (Luxán, 2007a: 170; Torres, 2007: 322). Después de la entrada masiva de tabacos por libra, las cantidades descendieron a 2,0 libras per cápita, reflejando con ello la mayor tasa de crecimiento de la población chilena de la primera mitad del siglo XIX. Como consecuencia, el gasto en tabaco alcanzó a 1,6 pesos per cápita en promedio durante el periodo en análisis (Cuadro 2). Dado que el nivel de salario efectivo de un peón urbano fluctuó en torno a los 68 pesos por año al final del periodo colonial (Pinto, 1976: 85; Quiroz, 2009: 229; 2012: 116; Llorca \& Navarrete, 2015: 84), el gasto promedio en tabaco, incluso para un individuo de aquella menor competencia, significó alrededor del 2,5\% de su ingreso. En consecuencia, la adquisición de tabaco fue probablemente generalizada entre la población santiaguina, incluso cuando se trataba de abastecer un hogar ${ }^{51}$ con un único asalariado de calificación mínima.

Con todo, más allá de la comparación de cifras entre regiones, para comprender de manera integral cuán importante fue este fenómeno en Santiago dentro de este concierto es necesario contrastar elementos adicionales. Uno de ellos tiene relación con la antigüedad del Estanco en Chile, cuyo funcionamiento desde 1753 se inscribió como el tercero después de Cuba (1717) y Perú (1752) (Fisher, 1999: 42; Escobedo, 2007: 220-221; Luxán \& Gárate, 2010: 173). Este prematuro monopolio, si bien respondió a la urgencia hacendística metropolitana, revela al mismo tiempo el dinamismo con que se observó

50. La cadena de valor del tabaco de Saña comenzaba a un precio de 0,6 real/mazo en origen, sin gastos de transportes ni enzurronamiento, en Escobar (2004: 44, 76). A Chile, vía Valparaíso, llegaba a un precio entre 7/8 real y 1 real por mazo, en LAVAUD (1996: 126, 129). Mismo monto al cual compraba la administración los tabacos nacionales en épocas de libre cultivo, en LAVAUD (1996: 36).

51. El número de integrantes se estima en torno a ocho individuos, en base a un promedio de 6,5 hijos por hogar (SALINAS, 2005: 13). Véanse también MELlafe y SALINAS (1988: 167-180) y SALINAS (2004: 395-404). 
esta actividad no solo en términos de lo lucrativo que debió ser para algunos comerciantes (Barros, 2001, vi: 142), sino también por el alto y extendido consumo de tabaco que percibían las autoridades respecto de la población chilena.

En complemento, no puede desconocerse la incidencia del factor demográfico sobre el consumo. Así lo demuestran, al menos en términos de ingresos totales del Estanco, los registros de distintas economías hispanoamericanas a fines del siglo XVIII (Gráfico 7). De acuerdo con estos antecedentes, el obispado de Santiago, tal como podría esperarse por su menor número relativo de habitantes, presentó niveles inferiores de ingresos que los virreinatos, de mayor concentración demográfica. De igual forma, el partido de Santiago, pese a su considerable consumo per cápita, presentó un nivel agregado más bajo que los grandes centros coloniales.

\section{GRÁFICO 7}

\section{Ingreso por ventas de tabaco en Hispanoamérica, fines del siglo XVIII}

Nueva España, 1795-1799

Lima, 1760-1764

Nueva Granada, 1796-1800

Obispado de Santiago, 1791-1799

Partido de Santiago, 1791-1799

Guayaquil, 1789-1791
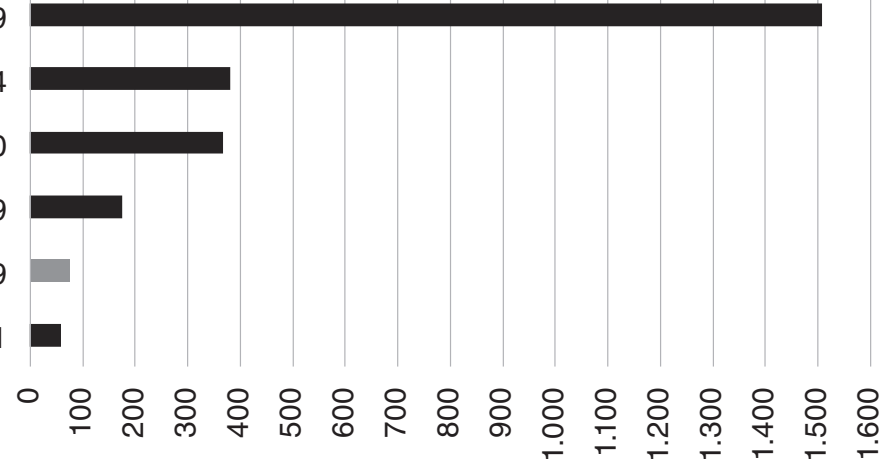

Miles de pesos de ocho reales

Fuentes: elaboración propia a partir de ANCH, FCM, serie 2, vol. 3155, fjs. 1-33; vol. 3156, fjs. 1-31; Laviana (1985: 90); Villalobos y Sagredo (2004: 86); Morales (2012: 45); Acevedo y Torres (2016: 290).

\section{CONCLUSIONES}

Sin considerar los efectos del contrabando ni el comercio ilícito, el consumo de tabaco en Santiago de Chile durante el periodo tardío colonial e inicios de la era republicana aumentó, en línea con el crecimiento de su población y pese al alza de sus precios medios. En términos de volumen, el consumo legal de tabaco alcanzó en promedio las 3,4 libras per cápita por año a fines del periodo colonial, mientras que en las primeras décadas republicanas bajó a niveles de 2,0 libras. Esta evolución se explicó por la transformación de la pauta de consumo santiaguina, cuya preferencia colonial por tabacos de menor ela- 
boración para labores de humo perdió terreno ante un mayor surtido de productos refinados después del periodo revolucionario que se inició en 1810. Durante esta transformación, los precios operaron de manera determinante, incentivando el abandono del tradicional hábito de aspirar tabaco en polvo por parte del grupo minoritario de mayor renta, por un lado, y promoviendo la demanda efectiva de los estratos medios e inferiores por tabacos de mejor manufactura, por otro.

Este acento en el fenómeno del consumo resalta, por tanto, el papel activo de la población santiaguina, cuyo acceso al tabaco debió ser universal, toda vez que este gasto representó tan solo un 2,5\% del ingreso efectivo anual de un trabajador con la menor calificación de la época. Un fenómeno que debió extenderse a todo Chile, al menos respecto de la mayoritaria población del obispado de Santiago, dadas las altas rentas asociadas al estanco y los volúmenes de tabaco que se evidencian durante buena parte del periodo en examen.

Con todo, estos resultados constituyen un nuevo elemento a favor de la denominada revolución del consumidor (Dobado, 2015: 19) y como consecuencia de la positiva condición de vida de la población de Santiago durante el inicio de la Era Moderna. Esto permite, por un lado, destacar este espacio económico, en contraste con las medidas de regiones específicas que suelen utilizarse como parámetros homogeneizantes de toda Hispanoamérica y, por otro, disponer de mayores antecedentes empíricos para avanzar en el conocimiento de los verdaderos estándares materiales de este extenso territorio, ambos elementos centrales en el actual debate sobre las causas de la gran divergencia. En concreto, la evidencia de este trabajo motiva la revisión de la canasta de consumo para la agregación del índice de precios correspondiente al periodo tardío colonial chileno, cuyo contenido solo incluye, en una proporción mínima, el gasto de tabaco en polvo (Ramón \& Larraín, 1982: 381).

Desde otra perspectiva, la atención sobre el consumo como elemento impulsor no solo de la cadena productiva y comercial tabaquera, sino también de los logros recaudatorios fiscales a escala regional, deja de manifiesto el contexto de liquidez en que operaba esta economía, a diferencia de la visión mayormente naturalizada con que se concibe a este espacio (Romano, 1965: 49-51). A través del comercio del tabaco en Santiago se visualiza cuán monetizada funcionaba esta economía durante la segunda mitad del siglo XviII, en contraste con la condición marginal con que se tilda a este espacio y Chile en general, donde se estipula que las capas "populares» sufrían permanentemente la falta de dinero para los intercambios (Romano, 1960: 20). Este trabajo muestra precisamente lo contrario por medio del extendido consumo de tabaco, en especial en rama, cuyo destino fueron los grupos de menores ingresos. 
Finalmente, el comercio de tabaco en Santiago, lejos de presentar un estado embrionario e irregular, tal como se aprecia en general la estructura del comercio interno chileno en el contexto tardío colonial (Carmagnani, 2001: 205), fue un sector dinámico debido a la activa participación de los estanqueros, cuyo número se determinaba según los requerimientos de la demanda, lo cual les aseguró altos niveles de ingresos, al menos en relación a una buena proporción de los trabajadores remunerados de la época. Esta actividad, cuya dinámica fue distinta al comercio local, constituyó un componente importante del complejo mercado interno colonial de Santiago (Martínez, 2016: 244-247), que llama a evaluar la visión convencional de los estándares de vida de su población, al menos con respecto a lo que hasta ahora señala la historiografía.

\section{AGRADECIMIENTOS}

Agradezco a los tres evaluadores anónimos de Historia Agraria sus valiosas observaciones y sugerencias de lecturas complementarias que permitieron mejorar este artículo. Así también a Enriqueta Quiroz, Julio Djenderedjian, Juan Luis Martirén y María Inés Moraes, quienes comentaron una versión preliminar de este trabajo que fue presentada en las IV Jornadas de la AMHE, Xalapa (México), febrero de 2017, y en el IV Congreso de la AHEC, San Andrés (Colombia), noviembre de 2017.

\section{REFERENCIAS}

ACEVEDo, A. \& TorRes, J. (2016). La renta de tabaco en la Nueva Granada, 1744-1850: Administración, comercio y monopolio. Comercio y economía, (30), 281-303. http://www.scielo.org.co/pdf/soec/n30/n30a12.pdf

Alemparte, J. (1966). El cabildo en Chile Colonial. Santiago: Andrés Bello.

Allen, R. C., Murphy, T. E. \& SChneIDer, E. B. (2012). The Colonial Origins of the Divergence in the Americas: A Labor Market Approach. The Fournal of Economic History, 72 (4), 863-894.

Alonso, L. (2006). Pautas de consumo y cambio tecnológico: La evidencia del tabaco en España, 1735-1886. En L. Alonso, L. GÁlveZ \& S. DE LuXÁN (Eds.), Tabaco e historia económica: Estudios sobre fiscalidad, consumo y empresa (siglos XVII-XX) (pp. 247270). Madrid: Fundación Altadis.

Amaty Junient, M. DE (1947). Memoria de gobierno [1761-1776]. Edición y estudio preliminar deV. Rodríguez \& F. Pérez. Sevilla: Escuela de Estudios Hispano-Americanos. 
Arroyo, L., Davies, E. \& Zanden, J. L. van (2011). Between Conquest and Independence: Real Wages and Demographic Change in Spanish America, 1530-1820. Center for Global Economic History Working Papers, (20), 1-49.

Assadourian, C. S. (1983). El sistema de la economía colonial: El mercado interior, regiones y espacio económico. México, DF: Nueva Imagen.

Barros, D. (2001 [1886]). Historia General de Chile. T. vi y viI. Santiago: Universitaria.

Calderón, A. (2016). Mirando a Nueva España en otros espejos: Cuatro ensayos sobre demografía y niveles de vida, siglos XVI-XIX. Tesis de doctorado. Madrid: Universidad Complutense de Madrid.

CARMAgnani, M. \& Klein, H. (1965). Demografía histórica: La población del obispado de Santiago 1777-1778. Boletín de la Academia Chilena de la Historia, (72), 57-74.

CARMAGNANI, M. (2001 [1973]). Los mecanismos de la vida económica en una sociedad colonial: Chile 1680-1830. Santiago: DIBAM.

Carrera, M. (1949). The Evolution of Weights and Measures in New Spain. The Hispanic American Historical Review, 29 (1), 2-24.

CAVIERES, E. (2008 [1996]). El comercio chileno en la economía mundo colonial.Valparaíso: Ediciones Universitarias de Valparaíso.

Carvallo, V. (1876). Segunda parte de la descripción histórica-jeográfica del Reino de Chile. Santiago: Impr. de la librería del Mercurio. (Colección de historiadores de Chile y documentos relativos a la historia nacional, 10).

Deans-Smith, S. (1999). El estanco del tabaco en el México borbónico. En A. GonzÁLEZ ENCISO \& R. TORRES (Eds.), Tabaco y economía en el siglo XVIII (pp. 79-106). Pamplona: EUNSA.

DíAz, J., LÜDERs, R. \& WAGNER, G. (2016). Chile 1810-2010: La República en cifras. Historical Statistics. Santiago: Ediciones UC.

Dobado, R. \& García Montero, H. (2009). Colonial Origins of Inequality in Hispanic America? Some Evidence on Wages and Heights. Documento presentado en «A Comparative Approach to Inequality and Development: Latin America and Europe». Madrid, 8-9 de mayo.

Dobado, R. \& García Montero, H. (2014a). Neither so Low nor so Short: Wages and Heights in Bourbon Spanish America from an International Comparative Perspective. Fournal of Latin American Studies, 46 (2), 291-321.

Dobado, R. \& García Montero, H. (2014b). El bienestar económico y biológico en la América borbónica: Una comparación internacional de salarios y estaturas. En J. GELMAN, E. LloPIS \& C. MARICHAL (Coords.), Iberoamérica y España antes de las independencias, 1700-1820: Crecimiento, reformas y crisis (pp. 481-523). México, DF: Instituto de Investigaciones Dr. José María Luis Mora/Consejo Nacional de Ciencia y Tecnología/El Colegio de México.

Dobado, R. (2009). Herencia colonial y desarrollo económico en Iberoamérica: Una crí- 
tica a la «nueva ortodoxia». En E. Llopis \& C. MARICHAL (Coords.), Latinoamérica y España 1800-1850: Un crecimiento económico nada excepcional (pp. 253-291). México, DF: Instituto de Investigaciones Dr. José María Luis Mora.

Dobado, R. (2015). Pre-Independence Spanish Americans: Poor, Short and Unequal... or the Opposite? Revista de Historia Económica-fournal of Iberian and Latin American Economic History, 33 (1), 15-59.

Encina, F. A. (1970 [1954]). Resumen de la Historia de Chile. T. I y II. Santiago: Zig-Zag. Escobar, M. (2004). El tabaco en el Perú Colonial 1752-1796. Lima: Universidad Nacional Mayor de San Marcos.

EscoBEDo, R. (2007). La expansión geográfica de la renta del tabaco. Estudis, (33), 193224.

FisHer, J. (1999). El estanco del tabaco en el Perú borbónico. En A. GonZÁlez ENCISO \& R. TORReS (Eds.), Tabaco y economía en el siglo XVIII (pp. 35-53). Pamplona: EUNSA.

FolChI, M. \& López, M. (2010). Los ingresos de la Real Hacienda en la Caja Real de Santiago de Chile, 1700-1810. Documento presentado en el II Congreso Latinoamericano de Historia Económica (CLADHE-II). Ciudad de México, 3-5 de abril. http://www.economia.unam.mx/cladhe/registro/ponencias/587_abstract.pdf

Garavaglia, J. C. (1983). Mercado interno y economía colonial. México, DF: Grijalbo. GonZÁlez Enciso, A. (2006). Tabaco y Hacienda, 1670-1840. En L. Alonso, L. GÁLVEZ \& S. DE LUXÁN (Eds.), Tabaco e historia económica: Estudios sobre fiscalidad, consumo y empresa (siglos XVII-XX) (pp. 43-70). Madrid: Fundación Altadis.

GonZÁleZ FERnÁNDEZ, D. (1999). Tabaco y poder: La primera factoría de La Habana. En A. GonzÁlez Enciso \& R. ToRres (Eds.), Tabaco y economía en el siglo XVIII (pp. 107-122). Pamplona: EUNSA.

Grafe, R. \& IrIgoIn, M. A. (2006). The Spanish Empire and its Legacy: Fiscal Redistribution and Political Conflict in Colonial and Post-Colonial Spanish America. Fournal of Global History, 1 (2), 241-267.

GRUPO DE Estudios DEL TABACo (GRETA) (2002). El consumo de tabaco en España en el siglo XVIII. Cuadernos de investigación histórica, (19), 313-345.

IrIgoIN, M. A. \& GRAFE, R. (2006). Bargaining for Absolutism: A Spanish Path to Nation State and Empire Building. Discussion Papers in Economic and Social History, (65), 4-43.

Johnson, L. L., Socolow, S. M. \& SeIBerT, S. (1980). Población y espacio en el Buenos Aires del siglo XviII. Desarrollo Económico, 20 (79), 329-349.

Klein, H. \& TePaske, J. (1982). Las cartas cuentas de la Real Hacienda de la América Española, siglos XVI a principios del siglo XIX. http://realhacienda.colmex.mx Kyonen, H. (1955). El estanco del Tabaco bajo Portales, Cea y Compañia:Años 1824-1826. 
Memoria de grado. Santiago: Universidad de Chile.

Lavaud, G. (1996). El estanco de tabaco, 1826-1846. Tesis de licenciatura. Santiago: Universidad Católica de Chile.

Laviana, M. L. (1985). El estanco del tabaco en Guayaquil. Temas Americanistas, (5), 68-105.

Llorca, M. \& Navarrete, J. (2015). The Real Wages and Living Conditions of Construction Workers in Santiago de Chile during the Later Colonial Period, 1788-1808. Investigaciones de Historia Económica, 11 (2), 80-90.

LlorCa, M. \& NAVARRETE, J. (2016). The Chilean Economy during the 1810-1830s and its Entry into the World Economy. Bulletin of Latin American Research, 36 (3), 354369.

LuXÁN, S. DE \& GÁRATE, M. (2010). La creación de un sistema atlántico del tabaco (siglos XVII-XVIII): El papel de los monopolios tabaqueros: Una lectura desde la perspectiva española. Anais de História de Além-Mar, (11), 145-175.

LuXÁn, S. DE (2007a). Solo Madrid es Corte: Del consumo suntuario protegido a la democratización del hábito de fumar, 1730-1804. En J. M. RodRíGUEZ GoRDILlo \& M. GÁRATE (Dirs.), El monopolio español de tabacos en el siglo XVIII, consumos y valores: Una perspectiva regional (pp. 109-189). Madrid: Fundación Altadis.

LuXÁN, S. DE (2007b). Canarias, una administración ultraperiférica de la renta del tabaco durante el siglo XVIII. En J. M. RodríGuez Gordillo \& M. Gárate (Dirs.), El monopolio español de tabacos en el siglo XVIII, consumos y valores: Una perspectiva regional (pp. 461-495). Madrid: Fundación Altadis.

Martínez Barraza, J. J. (2016). Comercio interior en el Corregimiento de Santiago, 17731778. Tesis de maestría. Santiago: Universidad de Chile.

Medina, J.T. (1960). Actas del Cabildo de Santiago durante el periodo llamado de la Patria Vieja (1810-1814). Santiago: Fondo Histórico y Bibliográfico José Toribio Medina.

Mellafe, R. \& Salinas, R. (1988). Sociedad y población rural en la formación de Chile actual: La Ligua, 1700-1850. Santiago: Universidad de Chile.

Morales, C. (2012). Mercantilismo y crecimiento económico en el virreinato del Perú: El Estanco del Tabaco 1750-1800. Investigaciones sociales, 16 (28), 35-47. http://revistasinvestigacion.unmsm.edu.pe/index.php/sociales/article/view/7376/6440

NÁTER, L. (2006). Engranajes del Imperio: El caso de los monopolios de tabaco en el siglo XViII. En L. Alonso, L. Gálvez \& S. DE LuXÁn (Eds.), Tabaco e historia económica: Estudios sobre fiscalidad, consumo y empresa (siglos XVII-XX) (pp. 205-29). Madrid: Fundación Altadis.

O'Brien, P. (1982). European Economic Development: The Contribution of the Periphery. The Economic History Review, 35 (1), 1-18. http://www.jstor.org/stable/2595100 Pérez García, J. (1900). Historia de Chile. T. I. Santiago: Impr. Elzeviriana. (Colección 
de historiadores de Chile y documentos relativos a la historia nacional, 22 y 23). PINTO, S. (1976). Vías y medios de comunicación en Chile durante el siglo XVIII. Santiago: Universidad de Chile.

Quiroz, E. (2006). El consumo como problema histórico: Propuestas y debates entre Europa e Hispanoamérica. México, DF: Instituto Mora.

Quiroz, E. (2009). Salarios y condiciones de vida en Santiago de Chile, 1785-1805. En E. Quiroz \& D. Bonnet (Coords.), Condiciones de vida y trabajo en la América Colonial: Legislación, prácticas laborales y sistemas salariales (pp. 211-264). Bogotá: Universidad de Los Andes-CESO.

Quiroz, E. (2012).Variaciones monetarias, impulso urbano y salarios en Santiago en la segunda mitad del siglo XviII. Historia, 45 (1), 91-122.

RAMÓN, A. DE \& LARRAín, J. M. (1982). Orígenes de la vida económica chilena: 1659-1808. Santiago: Centro de Estudios Públicos.

RAMón, A. DE (2007). Santiago de Chile (1541-1991): Historia de una sociedad urbana. Santiago: Catalonia.

Rodríguez Gordillo, J. M. \& GÁRATe, M. (Dirs.) (2007). El monopolio español de tabacos en el siglo XVIII, consumos y valores: Una perspectiva regional. Madrid: Fundación Altadis.

RodríGUEZ Gordillo, J. M. (2007). La renta del tabaco en el primer tercio del siglo XVIII. En J. M. RodríGUez Gordillo \& M. GÁRATE (Dirs.), El monopolio español de tabacos en el siglo XVII, consumos y valores: Una perspectiva regional (pp. 25-105). Madrid: Fundación Altadis.

Romano, R. (1960). Una economía colonial: Chile en el siglo XviII. Annales, (2), 1-31. Romano, R. (1965). Una economía colonial: Chile en el siglo XVIII. Buenos Aires: Editorial Universitaria de Buenos Aires.

SAlINAS, R. (1974-1975). Raciones alimenticias en Chile colonial. Historia, (12), 57-76. SALINAS, R. (2004). Historia de la familia chilena. En P. RodRígueZ (Coord.), La familia en Iberoamérica, 1550-1980 (pp. 390-427). Bogotá: Universidad Externado de Colombia/Convenio Andrés Bello.

SALINAS, R. (2005). Población, habitación e intimidad en el Chile tradicional. En R. SAGREDO \& C. GAZMURI (Dirs.), Historia de la vida privada en Chile. I: El Chile tradicional: De la conquista a 1840 (pp. 11-47). Santiago: Taurus.

SANTILLI, D. \& GELMAN, J. (2016). Los estudios sobre el nivel de vida: La metodología de la canasta aplicada a la primera mitad del siglo XIX porteño. Folia Histórica del Nordeste, (26), 126-138.

SiLva, F. (1968). Perú y Chile: Notas sobre sus vinculaciones administrativas y fiscales (1785-1800). Historia, (7), 147-203.

SOCIEDAD BIBLIOGRÁFICA DE SANTIAGO (1895). La provincia eclesiástica chilena, erección 
de sus obispados y división en parroquias. Freiburg im Breisgau: Impr. de la Casa Editorial Pontificia de B. Herder.

Solbes, S. (2007a). Consumos y valores de la renta del tabaco en la administración provincial del Reino de Valencia, 1731-1798. En J. M. RodríGUEZ Gordillo \& M. GÁRATE (Dirs.), El monopolio español de tabacos en el siglo XVIII, consumos y valores: Una perspectiva regional (pp. 269-291). Madrid: Fundación Altadis.

SOLBES, S. (2007b). Consumos y valores de la renta del tabaco en la administración provincial del Reino de Navarra, 1731-1799. En J. M. RodRíGUEZ Gordillo \& M. GÁRATE (Dirs.), El monopolio español de tabacos en el siglo XVIII, consumos y valores: Una perspectiva regional (pp. 437-459). Madrid: Fundación Altadis.

STAPFF, A. (1961). La renta del tabaco en el Chile de la época virreinal. Anuario de Estudios Americanos, (XVIII), 1-63.

TorRes, R. (2007). El consumo del tabaco en Cataluña durante el siglo XviII. En J. M. RODRíGUEZ GoRdillo \& M. GÁRATE (Dirs.), El monopolio español de tabacos en el siglo XVIII, consumos y valores: Una perspectiva regional (pp. 293-335). Madrid: Fundación Altadis.

Villalobos, S. \& Sagredo, R. (2004). Los estancos en Chile. Santiago: Fiscalía Nacional Económica/Centro de Investigaciones Diego Barros Arana.

Vizcarra, C. (2006). El monopolio del tabaco en Hispanoamérica colonial. En L. Alonso, L. GÁlvez \& S. DE LuXÁN (Eds.), Tabaco e historia económica: Estudios sobre fiscalidad, consumo y empresa (siglos XVII-XX) (pp. 231-244). Madrid: Fundación Altadis. 